NUREG/CR-6022

BNL-NUREG-52370

\title{
High Pressure Coolant Injection (HPCI) System Risk-Based Inspection Guide For Browns Ferry Nuclear Power Station
}

Preparced by

s. Wong, A. Dibiasio, W. Ciunther

Brookhaven National Laboratory

Prepared for

U.S. Nuclear Regulatory Commission
1150

E66. 02150

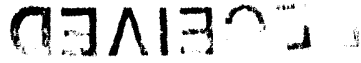




\section{AVAILABILITY NOTICE}

Availability of Reterence Materials Cited in NRC Publications

Most documents clted in NAC publlcations will be avallable from one of the following sources:

1. The NAC Public Document Room, 2120 L Street, NW, Lower Level, Washington, DC 20555-0001

2. The Superintendent of Documents, U.S. Government Printing Office, Mall Stof SSOP, Washington. DC 20402-9328

3. The National Technical Information Service, Springfleid, VA 22161

Although the Hsting that follows represents the majority of documents cited in NRC publlcations, it is not intended to be exhaustive.

Referenced documents avallable for inspection and copying for a fee from the NRC Publle Document Room Include NRC correspondence and internal NRC memoranda; NRC Office of inspection and Enforcement bulletins. circulars. Information notlces. Inspection and Investigation notices; Licensee Event Reports; vendor reports and correspondence; Commission papers; and applicant and licenseo documents and correspondence.

The following documents in the NUREG serles are avallable for purchase from the GPO Sales Program: formal NRC staff and contractor reports, NRC-sponsored conference proceedings, and NRC booklets and brochures. Also avallable are Regulatory Guldes. NRC regulations in the Code of Federal Regulations, and Nuclear Regulatory Commission Issuances.

Documents avallable from the National Technical Information Service Include NUREG series reporis and technical reports prepared by other federal agencles and reports prepared by the Atomic Eneroy Commission. forerunner agency to the Nuclear Regulatory Commission.

Documents avallable trom public and special technical libraries include all open Vterature items, such as books, Journal and periodical articles, and transactions. Federal Register notices, federal and state legislation. and congressional reports can usually be obtained from these llbraries.

Documents such as theses, dissertations, forelgn reports and translations, and non-NRC conference proceedings are avallable for purchase from the organization sponsoring the publication cited.

Single coples of NRC draft reports are avallable free, to the extent of supply, upon written request to the Office of Information Resources Management. Distrlbution Section. U.S. Nuclear Regulatory Commlesion. Washington, DC 20555-0001.

Coples of Industry codes and standards used in a substantive manner in the NRC regulatory process are maintalned at the NRC LIbrary, 7920 Norfolk Avenue, Bethesda, Maryland, and are avallable there for reference 480 by the public. Codes and standards are usually copyrighted and may be purchased from the originating organlzation or. If they are American Natlonal Siandards, from the American National Standards Institute, 1430 Broadway. New York, NY 10018.

\section{DISCLAIMER NOTICE}

This report was prepared as an account of wcrk sponsored by an agency of the United States Government. Neither the United States Government nor any agency thereot, or any of their employees, makes any warranty. expresed or implied, or assumes any legal l ability of responsibility for any third party's use, or the results of such use, of any information, apparatus, prajuct or process disclosed in this report, or represents that its use by such third party would not intringe privately owned rights. 
NUREG/CR-6022

BNL-NUREG-52370

\section{High Pressure Coolant Injection \\ (HPCI) System Risk-Based \\ Inspection Guide For Browns \\ Ferry Nuclear Power Station}

Manuscript Completed: August 1993

Date Pubished: September 1993

Prepared by

S. Wong, A. DiBiasio, W. Gunther

J. Chung. NRC Project Manager

Brookhaven National Laboratory

Upton, NY 11973

Prepared for

Division of Systems Safety and Analysis

Office of Nuclear Reactor Regulation

U.S. Nuclear Regulatory Commission

Washington, DC 20555-0001

NRC FIN A3875 


\begin{abstract}
The High Pressure Coolant Injection ( $\mathrm{HPCl}$ ) system has been examined from a risk perspective. A System Risk-Based Inspection Guide (S-RIG) has been developed as an aid to HPCl system inspections at the Browns Ferry Nuclear Power Plant, Units 1, 2 and 3. The role of the $\mathrm{HPCl}$ system in mitigating accidents is discussed in this S-RIG, along with insights on identified risk-based failure modes which could prevent proper operation of the system.

The S-RIG provides a review of industry-wide operating experience, including plant-specific illustrative examples to augment the PRA and operational considerations in identifying a catalogue of basic PRA failure modes for the HPCI system. It is designed to be used as a reference for routine inspections, self-initiated safety system functional inspections (SSFIs), and the evaluation of risk significance of component failures at the nuclear power plant.
\end{abstract}




\section{CONTENTS}

Page

ABSTRACT ............................

EXECUTIVE SUMMARY $\ldots \ldots \ldots \ldots \ldots \ldots \ldots \ldots \ldots \ldots \ldots \ldots \ldots$

ACKNOWLEDGMENTS $\ldots \ldots \ldots \ldots \ldots \ldots \ldots \ldots \ldots \ldots \ldots \ldots$

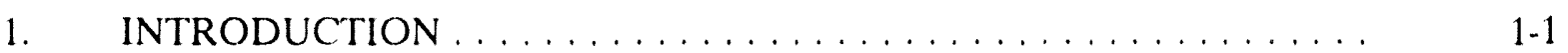

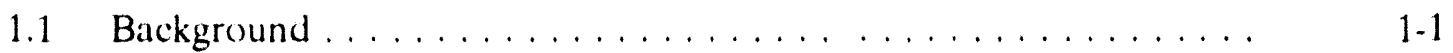

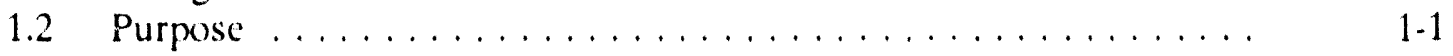

1.3 Application to Inspections . . . . . . . . $\ldots \ldots \ldots \ldots \ldots$

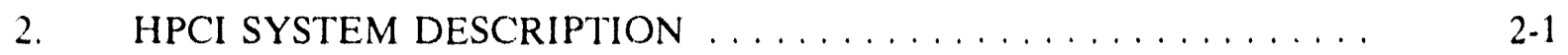

3. ACCIDENT SEQUENCE DISCUSSION ..............

3.1 Loss of High Pressure Injection and Failure to Depressurize . . . . . 3-1

3.2 Station Blackout $(\mathrm{SBO})$ With Intermediate Term Failure
of High Pressure Injection $\ldots \ldots \ldots \ldots \ldots \ldots \ldots \ldots \ldots \ldots \ldots \ldots$

3.3 Station Blackout with Short Term Failure of High Pressure

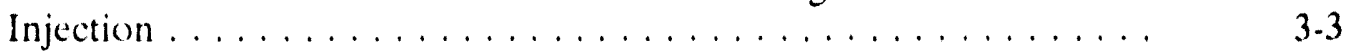

3.4 ATWS With Failure of RPV Water Level Control at High

Pressure .......................... 3-3

3.5 Unisolated LOCA Outside Containment . . . . . . . . . . . . $3-4$

3.6 Overall Assessment of HPCI Importance in the Prevention of

Core Damage ........................ $3-5$

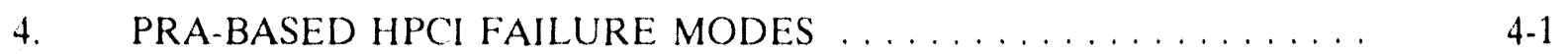

5. HPCI SYSTEM WALKDOWN CHECKLIST BY RISK IMPORTANCE $5-1$

6. OPERATING EXPERIENCE REVIEW ............... $6-1$

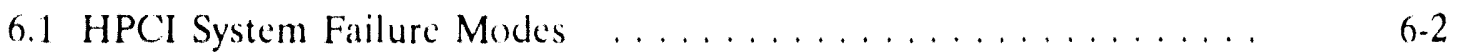

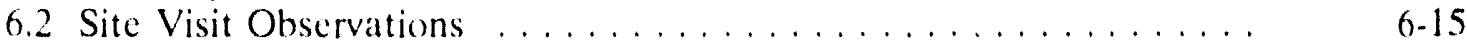

6.3 Contribution of Human Errors to System Unavailability .........

6.4 Additional System Considerations ................. 6 .18

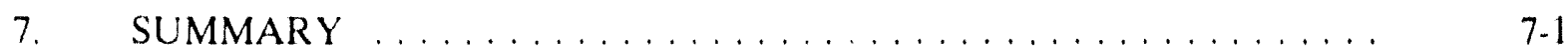

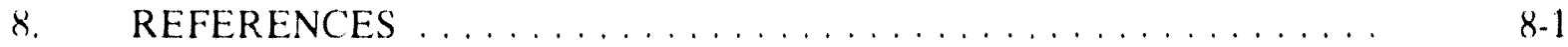

\section{APPENDICES}

A-1 SUMMARY OF INDUSTRY SURVEY OF HPCI OPERATING EXPERIENCE HPCI PUMP OR TURBINE FAILS TO START OR RUN ......... A-1

A-2 SELECTED EXAMPLES OF ADDITIONAL. HPCI FAILURE MODES IDENTIFIED DURING INDUSTRY SURVEY 


\section{FIGURES}

Figure No. $\quad \underline{\text { Page }}$

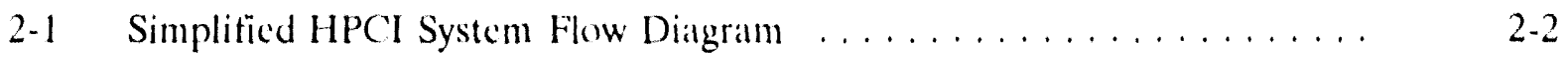

\section{TABLES}

Table No. Page

4-1 Summary of PRA-Based Failure Modes for the HPCI System . . . . . . $\quad 4-3$

4-2 Browns Ferry Nuclear Plant HPCl System LER Survey Compared with Industry Experience $\ldots \ldots \ldots \ldots \ldots \ldots \ldots \ldots \ldots \ldots \ldots \ldots$ 4.4

5-1 Browns Ferry Plant HPCI System Walkdown Checklist . . . . . . . . $\quad 5-2$

$6-1 \quad \mathrm{HPCl}$ System Failure Summary $\ldots \ldots \ldots \ldots \ldots \ldots \ldots \ldots \ldots \ldots$

6-2 HPCI Pump or Turbine Fails to Start or Run -

Failure Subcategories . . . . . . . . . . . . . . . . . . . . . 6 .3

A-1 HPCI Pump or Turbine Fails to Start -Industry Survey Results . . . . . . . A-2

A-2 Summary of Illustrative Examples of Additional HPCI Failure

Modes . . . . . . . . . . . . . . . . . . . . . . . . . 


\section{EXECUTIVE SUMMARY}

This System Risk-Based Inspection Guide has been developed as an aid to HPCI system inspections at the Browns Forry Nuclear (BFN) Plant. The document presents a risk-based discussion of the role of the HPCI system in accident mitigation and provides a catalogue of PRA. based HPCI system failure modes (Sections 3 and 4). Most PRA oriented inspection plans contain these prerequisite information; however, the inspector(s) has to rely on his experience and knowledge of plant-specific and BWR plant operating histories to aceomplish the inspection objectives. Thus, this system RIG integrates insights from industry-wide experience with PRA and other operational considerations to augment the catalogue of basic PRA-derived failure modes for use by the inspector(s).

Risk-based input and insights from the operating experienee database have been combined to develop a set of composite rankings of failure modes for the HPCI system. Table 4.2 shows the ranking of these HPCI system failure modes. This information can be used to optimize NRC resources by properly allocating proative inspection efforts based on risk eonsiderations and industry experience. In this regard, the more important or unusual component fiults in the HPCI system are reflected in the system walkdown checklist presented in Section 5. Along with the assessment of the operating experience discussed in Section 6, this checklist provides guidance on potential areats of NRC oversight both for routine inspections and the "post mortems" conducted after the oceurrence of significant faulures. Appendices A-1 and A-2 provide detailed information on selected failure events that were observed in the industry-wide operating experience. This information can also be utilized by the inspector(s) to have further insights on a particular component failure mode and provide the rationale for inspection emphasis.

A comparison of the distribution of HPCI system failure events between the BFN plant and industry-wide BWR operating experienee is presented in Table 4-2. Although the plant specific operating experience data are limited (becaluse the BFN plant units were in cold shutdown for about half of the evaluation peried). the plant specific LER frequency for some HPCI system failure modes was higher than that observed in the industry-wide survey results. These component failures are candidates for greater attention in the inspection efforts and thus, the generic prioritization of plant components for inspection focus should be adjusted aceordingly to retlect the observed distribution of failures. Beciluse the distribution of plant specific component failures in the HPCI system is expected to vary in time (c.g., modifications may reduce or climinate a number of chronic problems), the generic ranking of HPCI system failure modes developed in this report has not been revised to reflect the presently available BFN plant LER database.

As the BFN plant matures in its operatting liferime, the knowledge feedback of operational experience is assimilated by the utility's statt and reflected in the plant procedures. Therefore, the incidence of failure events such as inadvertent $\mathrm{HPCI}$ system isolations during the performance of surveillance and calibration activities is expected to decrease becaluse of improved knowledge of the system operations. However, component failures due to aging-related caluses are expected to become a significant contributor to the frequency of BFN plant HPCI system failures. Review of ind stry-wide operating experience has identified several HPCl system failure events due to component aging problems in the pump and turbine control equipment at a few older BWR plants (c.g., Duane Arnold. Hattch, Cooper, and Brunswick) including the Browns Ferry nuclear plant. It 
is noted that there is a concerted effort at the BFN plant to upgrade the HPCI system control equipment that would preclude the effects of component obsoleseence, improve system reliability and thus, enhance HPCI system availability.

Review of the BFN plant operational experience in this report included all HPCI systemrelated LERs generated from 1980 to mid 1992. Subsequently issued LERs ean be eorrelated with the PRA-derived failure eategories, and then used to update the distribution of plant specifie $\mathrm{HPCI}$ system failures. A comparison of this updated database with the more static failure distribution of HPCI failure events for the entire population of BWR plants can provide insights on certain trends of recurrent problems that warrant additional inspection oversight as the plant ages.

Recommendations have been made throughout this document regarding the emphasis or focus of inspection activities for the $\mathrm{HPCl}$ system at the BFN plant. Some of these suggestions are generic in nature, but some recommendations related to specific maintenance, testing, or operational activities conducted at the BFN plant are made to assure that a highly reliable operation of the HPCI system is maintained. These recommendations could also be useful to the licensee in planning and conducting self-initiated safety system functional inspections (SSFIs) on various safety systems including the HPCI system to ensure functional adequacy and operational readiness of a plant system. Some of the specifie recommendations for greater attention in future inspections are:

1. The inspector(s) should examine the surveillance and maintenance frograms for the emergency diesel generators and the plant procedures for the recovery of either the $500 \mathrm{kV}$ or $161 \mathrm{kV}$ offsite power supply during a loss of offsite power event. In addition, the training program should be periodically reviewed to assure a continued awareness of temporary connections, various contingency measures, and procedures for suceessful DC load shedding required to cope with SBO-type conditions. |Pige 3-2]

2. The plant lieensec actions to monitor and control the temperature conditions in the $H^{\text {nel }}$ room should be reviewed and the effects of loss of room cooling on long term operation of the HPCI system should be evaluated It is noted that there are no room coolers in the BFN plant HPCI room. |Pages 3-3 and (6-19)

3. Within the context of using the HPCI system in an ATWS event, the capability of the licensee to perform the necessary bypasses of the system trip logic should be evaluated periodically. [Pige 3-4]

4. The turbine exhaust rupture disks should be installed with a structural backing to prevent cyclic tatiguc tailures. [Page 6-7]

5. The inspector(s) should confirm that there is adequate oversight on the moditications, operations, maintenance and surveillances of the turbine speed control subsystem to ensure functional adequacy of the overall system. [Page (6-4)

6. Lieensee responses to NRC Bulletin 88 -(1) should be reviewed to alssess the adeyuacy of the design of the minimum flow bypass line. Page $0-1+1$ 


\section{ACKNOWLEDGMENTS}

The authors express their sincere appreciation to the NRC Program Manager for this project, Dr. J.W. Chung, for his technical direction, and to the NRC Licensing Project Manager, Mr. Thierry M. Ross, and NRC Resident Inspector at the BFN plant, Mr. R. Musser, for their assistance at the site visit.

We are also thankful to Mr. M. Morrison of TVA Licensing and his staft at the BFN plant for the voluntary participation in discussions and providing valuable comments on this report.

Finally, we wish to thank Ann Fort for her help in the preparation of this manuscript. 


\section{INTRODUCTION}

\subsection{Background}

Probabilistic risk assessment (PRA) is a comprehensive, integrated analysis of the diverse aspects of design, operation, and minintenance of a plant to provide a snapshea of risks. A probabilistic risk analysis may reveal the features of the plant design that merit further attention and thus, provide a focus for improving saffety. In a study sponsored by the U.S. Nuclear Regulatory Commission. Brookhaven National Laboratory (BNL) has developed and applied a methodology for providing plant specific risk-based inspection guidance for the High Pressure Coolant Injection (HPCl) system in boiling water reactor (BWR) plants that do not have a PRA study. This methodology uses insights from existing PRA studies and plant-specific operating experience for consideration in inspection planning at the nuclear power plant selected for study.

\subsection{Purnose}

This HPCI System Risk-Based Inspection Guide (S-RIG) hats been developed as an aid to NRC inspection activities at the Browns Ferry Nuclear Power Station. The High Pressure Coolant Injection (HPCI) system has been examined from a risk perspective. Common BWR accident seyuences that involve the HPCI system are described in Section 3 to provide a review of the system's accident mitigation function and to identify system unavailability combinations that can greatly increase risk exposure. Section 4 provides the description and prioritization of the PRAbased HPCI system failure modes for inspection purposes. In Section 5 , risk signiticant failure modes are identitied in a system walkdown guide for inspection emphasis. Results of a BWR uperating experience review are presented in Section 6 along with additional information in related areas such as HPCl support systems, human crrors, and system interactions that affect the availability of the HPCI system. A summary of insights from the Browns Ferry plant operating experience review is provided in Section 7.

\subsection{Application to Inspections}

This inspection guide can be used as a reference for routine inspections and for identifying the significance of eomponent failures that occur at the Browns Ferry Nuclear Power Plant. The information presented in Sections 4 and 5 can be used to prioritize day-to-day inspection activities. This S.RIG is also useful for NRC inspection activities in response to unusual event occurrences resulting from system failures. The accident sequence descriptions presented in Section 3 together with the discussion of multiple system unavailability (Section 6), provide some insight into the combinations of system outages that can greatly increasc risk. Within the context of the HPCI system, review of the operating experience data provides insights on some of the more unusual failure mechanisms (including corrective actions) that would be useful in the review of the licensee response to a system failure. Recurrent component failures identified in this system RIG can also be used for trending purposes to point out unique problems. Table 4.2 provides a summary of the industry wide distribution of HPCI failure events, and presents a comparison of the Browns Ferry HPCI system failure history with industry experience. Certain HPCI system failure modes (e.g., inverter trips or failures, turbine stop valve fitilures, turbine exhaust rupture disk failures, and CST/suppression pool switchover logic fatilures) appear to account for a large fraction of the $\mathrm{HPCl}$ 
system failures at the Browns Ferry nuclear plant and therefore, are candidates for increased inspection surveillanees. These problem areas should be reviewed periodically as additional and new data of plant-specific operating experience are compiled. 


\section{HPCI SYSTEM DESCRIPTION}

At each Browns Ferry Nuclear Plant unit, the High Pressure Coolant Injection (HPCI) system is a single train system consisting of steam turbine-driven injection and booster pumps, a gland seal condenser, piping, valves, controls, and instrumentation. A simplified tlew diagram of the system for Browns Ferry Nuclear Plant Unit 2 is shown in Figure 2-1. The system is designed to pump a minimum of $500(0) \mathrm{gpm}$ into the reactor vessel over a range of reactor pressures from 150 to 1120 psig when automatically activated by a low-low reactor water level ( -45.0 inches) or high drywell pressure $(2.45 \mathrm{psig})$ signal, or when manually initiated from the control room. Each automatic initiation signal is generated from a "one-out-of-two-twiec" logie in which at least one division I logic channel and one division 11 logic channel in either the low reactor water level logic or the high drywell pressure logic must be actuated. Two sourees of coo! !ng water are available for the $\mathrm{HPCl}$ system. Initially, the HPCl pump takes suction from the condensate storage tank (CST) through a normally open motor-operated valve, 2-FCV-73-40. The pump suction automatically transfers to the suppression pool on low CST level or high suppression pool level. This transfer is accomplished by a signal that opens the suppression pool suction valves, 2-FCV-73-26 and 2-FCV. 73-27. Onee these valves are fully open, stem-mounted limit switches automatically actuates to ilose the CST suction valve. There is a 5 -second time delay for the switchover on high suppression pool level conditions. Events that raise the suppression pool temperature above the HPCl system design limits of temperature for the suction souree may require a manual suction transfer back to the CS:

Upon HPCI system initiation, the normally closed injection valve 2-FCV-73-44 automatically opens to allow water to be pumped into the reactor vessel through a series of eheck valves in the main feedwater line A. A minimum-flow bypass line is provided for pump protection. When the bypass valve 2-FCV-73-30 is open. flow is directed to the suppression pool. A full-flow test line is also provided to recirculate water back to the CST. The two isolation valves, 2-FCV-73-35 and 2 . FCV-73-36, are equipped with interlocks to automatically close the test line (if open) upon the generation of an HPCl system initiation signal.

The HPCI pump turbine is driven by reactor steam. The inboard and outboard HPCI system isolation valves in the steam line to the HPCI turbine, 2-FCV-73-2 and 2-FCV-73-3, are normally open to keep the piping, to the turbine in a hot and pressurized eondition which permits rapid startup of the HPCI sysam. U'pon receiving a signal from the HPCl system isolation logic, these valves will close and cannot be reopened antil the isolation signal is cleared and the logic is reset. Inboard isolation valve 2-FCV.73-2 is powered from the 480 VAC Reactor MOV Board $2 \mathrm{~A}$ and controlled by the isolation logic system $A$; while the outhoard isclation valve 2-FCV-73-3 is powered from the 250 VDC Reactor MOV Board 2A and controlled by the isolation logic system B.

Steam is admitted to the HPCI pump turbine through steam supply valve 2-FCV-73-16, a turbine stop valve 2-FCV-73-18, and a turbine governor valve 2-FCV-73-19, all of which are normally closed and are opened by an HPCI system initiation signal. Exhaust steam from the turbine is discharged to the suppression pool, while condensed steam from the steam lines and leakage from the turbine gland seals are routed to a gland seal condenser. 


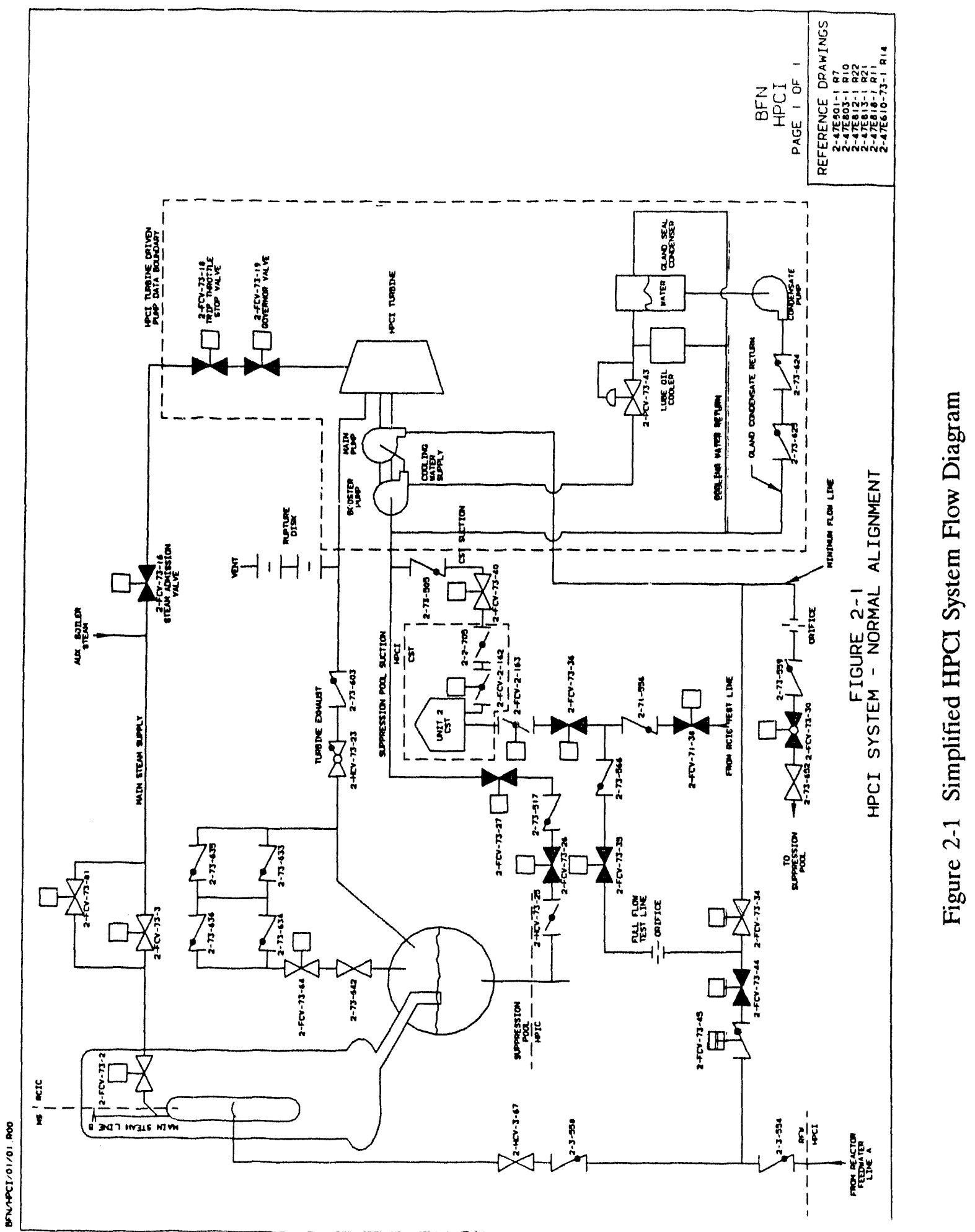




\section{ACCIDENT SEQUENCE DISCUSSION}

The role of the HPCI system in the prevention of reactor core damage provides valuable information that can be applied in the normal day-to-day inspection activities of the system. This information is readily available if a nuclear power plant has its own Probabilistic Risk Assessment (PRA) study. In addition to considerations of plant specitic design and operating nuanees, the risk information includes insights from the quantification and $p$ ioritization of postulated likelihood of accident sequences, system unavailabilities and component risk importances.

Since most nuclear power plants do not currently have PRAs, the application of risk insights to support audit and inspection activities is less straightforward. Thus, eight representative BWR accident sequences were developed from the review of available PRAs of BWR nuclear plants to provide a risk perspective for use in NRC inspection activities'. The contributions of these eight representative sequences account for an average of 87 pereent of the estimated core damage frequency due to internal event initiators in seven BWR plants. Because of operational and design similarities, generic risk insights from the characterization of these representative accident scenarios can be applied to other BWR plants for risk based inspections. This information can be used to allocate inspection resourees commensurate with risk importance. Since five of the eight representative sequences require the $\mathrm{HPCI}$ system to function for accident mitigation purposes, the generic risk information allows the inspector to focus attention on the important systems and plant components. These five accident sequences are discussed in the subsections below.

A PRA study of the Browns Ferry Unit 1 plant was performed as part of the NRC's Interim Reliability Evaluation Program (IREP) in 1982'. Six of the eight dominant accident sequences identified in the study involve failure to remove long-term decay heat from the reactor, while the other two scquences involve an anticipated transient without a scram (ATWS) event. Thus, the results of this study indicate that the residual heat removal system is the most important system at the Browns Ferry plant. However, the IREP studies and other early PRAs (e.g. WASH-1400) have conservatively assumed no recovery of the power conversion system subsequent to the accident initiator and the loss of all water injection into the reactor core following containment failure. Furthermore, no credit was given for venting capability because most BWR plants at that time did not have procedures to facilitate such action. These assumptions resulted in the likelihood of one accident sequence (i.e., loss of decay heat removal) to dominate the core damage frequency estimates and minimize the importance of other accident progressions and mitigating systems. Therefore, insights from this PRA study were not utilized in the characterization of generic BWR accident sequences and were of limited use in the evaluation of operational readiness of the HPCI system. Nothwithstanding these limitations, specific risk insights from the IREP study found to be applicable have been incorporated into the discussions on PRA-based failure modes presented in Section 6.1 .

\subsection{Loss of High Pressure Injection and Failure to Depressurize}

This sequence is initiated by a general transient (such as turbine trip with subsequent MSIV closure, loss of main feedwater, inadvertent SRV opening with MSIV closure, or loss of DC power), a loss of offsite power, or a small break LOCA event. The reactor successfully scrams. The power conversion system, including the main condenser, is unavailable either as a direct result of the initiator or due to subsequent MSIV closure. The high pressure injection systems ( $\mathrm{HPCI} / \mathrm{RCIC}$ ) fail to inject into the vessel. The major causes of $\mathrm{HPCI} / \mathrm{RCIC}$ unavailability include 
hardware failures (primarily turbine/pump faults, or pump discharge or steam turbine inlet valves failing to open) and system outages due to test or maintenance activities. The CRD hydraulic system can also be used as an alternate source of high pressure injection (HPI) at the Browns Ferry Nuclear Plant units in both normal and enhanced modes of operation. Failure of the second CRD pump during the enhaneed mode of operation (which require two-pump injection flow) or unsuccessful t?ow control station valving prevents sufficient injection into the reactor pressure vessel (RPV). The operator attempts to manually depressurize the RPV, cxcept that a common cause failure of the safety relief valves (SRVs) defeats both manual and automatic depressurization of the reactor vessel. The failure to depressurize the reactor vessel after HPI failure results in core damage due to a lack of vessel inventory makeup.

\subsection{Station Blackout (SBO) with Intermediate Term Failure of High Pressure Injection}

This sequence is initiated by a loss of offsite power (LOOP) even The emergency diesel generators (EDGs) are unavailable, primarily due to hardware faults. A secondary contributor to EDG unavailability are outages for maintenance activities. Support system malfunctions include EDG room or battery/switchgear room HVAC lailures, service water pump malfunctions, or EDG jacket cooler hardware failures. The $\mathrm{HPCI}$ and $\mathrm{RCIC}$ systems are initially available to provide reactor vessel inventory makeup.

The high pressure injection systems can provide inventory makeup until:

- the station batteries are depleted, or

- the system fails due to environmental conditions, i.e., high lube oil temperatures or high turbine exhaust pressure due to the high suppression pool temperature and pressure, or

- the RPV is depressurized wherein conditions can no longer support HPCI or RCIC system operation, or

- the HPCI system high area temperature logic isolates the system or long term exposure to high temperatures disables the turbine driven pump.

The Browns Ferry Unit 2 IPE analyses indicate that the LOOP scenario is the most important initiating event which results in the highest frequency accident sequences contributing to the overall plant core damage frequency $(\mathrm{CDF})^{3}$. The total frequency of all LOOP-initiated accident sequences comprise about 69 percent of the Browns Ferry plant CDF. Of these accident scenarios, about 27 percent of the Browns Ferry plant CDF result from LOOP sequences involving station blackout (SBO). SBO coping measures include successful DC load shedding which allows the battery lifetime to be extended to 4 hours and thus, assure the continued operation of the HPCI or RCIC systems to provide a source of water to the reactor core during that time. Plant procedures also address the recovery of either the $500 \mathrm{kV}$ or $161 \mathrm{kV}$ oftsite power supply within 6 hours to help reestablish water level control in the reactor vessel. In addition, the emergency procedures instruct the operators to utilize the residual heat removal service water (RHRSW) system (or the emergency equipment cooling water system as the backup) for water injection into the reactor vessel as a contingency measure if the SBO condition persists until decreasing reactor pressure (decay heat) can no longer support the HPCI or RCIC system operation. Once the reactor vessel is depressurized, these plant procedures guide the operators in establishing a "feed and bleed" path 
from the suppression pool to the reactor vessel and back to the suppression pool via the safety relief valves (SRVs) with heat removal via RHR heat exchangers.

The reactor building environmental conditions can also impact long term $\mathrm{HPCl}$ system operation. The reactor building HVAC and HPCI room cooling are dependent on AC power. Although the high area temperature isolation logic is not operable during SBO conditions at the Browns Ferry plant when DC battery power is depleted, there is an environmental qualification concern (e.g., operability of instrumentation and controls) if the $\mathrm{HPCl}$ pump room temperature approaches beyond $129^{\circ} \mathrm{F}$ under worse case conditions. The HPCI pump room does not have any room coolers, but it is open to the adjacent RHR quadrangle area which is ventilated automatically by room coolers that are activated on high temperature in the area. Plant procedures (2-EOI-3) address proper operator response to lower any high temperature condition in the HPCI room. The plant activities to monitor and control high area temperature during a SBO event should be reviewed. The review should include an audit of any calculations necessary to establish a time frame for the implementation of these activities.

\subsection{Station Blackout with Short Term Failure of High Pressure Injection}

This SBO sequence is similar to the previous sequence except the high pressure injection systems fail early. The sourees of emergency $A C$ power, i.e., the emergency diesel generators (EDGs), fail primanily due to hardware failures. Secondary contributors are: output breaker failures and EDG unavailability due to test or maintenance activities. Support system malfunctions such as service water supply failures in the EDG jacket cooling water train, battery/switchgear room HVAC failures, or test and maintenance unavailability, are significant contributors to the loss of on-site emergency AC power. Station battery failures (including common mode) within 4 hours are an important contributor to this seyuence, because the EDGs and HPI systems are dependent on DC power for instrumentation and control objectives.

This accident sequenee is a major contributor to the overall core damage risk at the Browns Ferry plant, primarily due to the short term failures of HPI systems (c.g., HPCI, RCIC and CRDH systems) and failure to recover AC power within 6 hours that prevent the possibility of cooling via the suppression pool source. The Browns Ferry IPE analyses indicate that the importance of HPCI/RCIC unavailability is assessed to be 0.1125 i.e., about 11.25 pereent of the plant CDF is contributed by accident sequences involving failure of the $\mathrm{HPCI}$ and RCIC systems. As such, the $\mathrm{HPCl} / \mathrm{RCIC}$ unavaliability estimates are a signiticint intluence on the total plant core damage trequency.

\subsection{ATWS with Failure of RPV Water Level Control at High Pressure}

This sequence is initiated by a transient event with initial or subsequent MSIV closure and a failure of the reactor protection system to provide an automatic scram. Attempts to manually scram are not suceessful; however, the Standby Liquid Control System (SLCS) is initiated. The condenser and the feedwater system are unavailable. The BWR Owner's Group Emergency Procedure Guidelines (EPGs) recommend RPV water level reductions for control of reactor power below $5 \%$ and the characterization of this BWR representative sequence was based on that philosophy. As evidenced by the EOI Program Manual Section III relating EPGs for development of emergency operating instructions, ATWS mitigation procedures at Browns Ferry Unit 2 are consistent with the philosophy of the BWROG guidance document. 
This sequence postulates a failure to ensure sufficient RPV makeup at high pressure to prevent core damage. There are two failure modes considered in this scenario:

1. The operator fails to control alceptable water level at high RPV pressure. This results in high reactor core power levels, continuous SRV discharges, and suppression pool heatup. After the suppression pool water reaches salturation, containment pressurization begins to oceur. High pressure injection fails due to high suppression pool temperature prior to containment failure.

2. The high pressure injection (HPCl) system fails, primarily due to pump failure to start or as a result of testing and maintenanee (T\&M) unavailability. Failure of injection or mintlow valves, inability of suction switchover, or loss of DC power are other potential system failures. HPCI pump failure to start or run, pump unavailability duc to testing and maintenanee activities, and Service Water EDG jacket cooler inlet or return valve failures are the major contributers to HPCI system failures.

The inability to maintain acceptable RPV water level above the top of the active fuel (TAF) requires manual emergency depressurization to allow the low pressure ECCS systems to inject wates, and thus prevent the onset of core damage.

The continued operability of the HPCI system during an ATWS event is eritical. Within the context of this accident sequence (i.e., time avaliable for success), the licensee capability to achieve the $\mathrm{HPCl}$ pump suction transfer in time and perform logic bypasses of the high turbine exhaust pressure trip that caluses a HPCI system isolation on high hack pressure should be evaluated periodically. With regard to HPCI system availability, the remaining sections will provide discussions on system failures and availability evaluation.

\subsection{Unisolated LOCA Outside Containment}

The accident initiator in this sequence is a high pressure boundary failure outside containment with a failure to isolate the rupture. The piping fialure is postulated in the following systems: main steam system $(60 \%)$, feedwalter system (12\%), high pressure injection system $(20 \%)$, and interfacing system piping lines $(8 \%)$. The percentiges in parentheses indicate the estimated relative contribution to core damage freguency due to piping firilures of each systemt.

An interficing systems LOCA event is defined as the initial pressurization of a low pressure piping line which results in a pressure boundary failure, compounded by the failure to isolate the failed piping line. The failure is typically postulated in a low pressure portion of the low pressure core spray (I.PCS) system, the LPCI system, shutdown cooling system, and (to a lesser extent), the HPCI or RCIC pump suction or the head spray line of RHR syctem.

The unisolated LOCA outside containment results in a rapid loss of the reactor coolant system (RCS) inventory and thus, eliminating the suppression pool as a long term source of RPV injection. Piping failures in the reactor building can also result in unfavorable environmental conditions for the Emergency Core Cooling Systems (ECCS). Unless the unaffected LCCS systems or the condensate system are avatilible, long term RPV injection is suspeet and core damage is likcly. 
There have been several HPCI pump suction overpressurization events, primarily during surveillance testing of the normally closed motor-operated HPCI injection valve 2-FCV-73-445. This is of particular concern for the discharge contiguration at the Browns Ferry plant that has a testable air-operated check valve in series with the normally closed MOV, because of the check valve's history of back leakage as observed in the industry-wide operating experience. The HPCI interfacing systems LOCA initiator seems to be less of a problem when the normally open valve 2 FCV-73-34 is closed prior to surveillane testing of the valve 2-FCV-73-44. However, some of the concerns regarding the previous test configuration are also valid here. There must be reasonable assurance that the normally closed 2-FCV-73-44 valve is leak tight during plant operation and prior to stroke testing. contirmation is necessary to assure that it is fully closed and will provide the necessary protectoon for the upstream piping. At the Browns Ferry plant, a one-inch relief valve 2 RFV-73-506 was installed in the HPCI booster pump suction piping to ensure the mitigation of overpressurization events. The valve is set to operate at 55 psig and is bench tested onee per plant refucling cycle to comply with ASME Code Section XI requirements.

\subsection{Overall Assessment of HPCI Importance in the Prevention of Core Damage}

As previously stated, the high pressure injection function (HPCI/RCIC/CRD) is important for mitigation purposes in tive of the eight representative BWR accident secpuences. The various system failures and their risk importances for all eight accident seyuences were prioritized by their contribution to overall core damage (using a normalized Fussell-Vescly importance measure). The HPI function, in aggregate, was assessed to fall in the high importance category. Other high risk important systems are the Emergency $A C$ Power system and the Reactor Protection system (RPS). The HPCI system itself is considered to be of medium risk importance, because of the multiple systems (e.g., RCIC and CRD systems) that can suceessfully provide vessel inventory makeup at high pressure. However, the Browns Ferry plant IPE analyses indicate that the importance of the HPCI system was assessed to be 0.16 , i.e. about 16 pereent of the plant core damage frequency were contributed by the likelihood of accident sequenees ir, rolving failure of the HPCI system. For comparison, other systems of medium risk importance are: the Standby Liquid Control, Automatic/Manual Depressurization, Service Water, and DC Power systems. 


\section{PRA-BASED HPCI FAILURE MODES}

PRA models are often used for inspection purposes to prioritize systems, components, and human actions in plant operational activities from a risk perspective. This enables the inspection effort to be apportioned based on a core damage prevention measure called risk importance. Risk importance measures (e.g., Fussell-Vesely importance measure) can be can be used to determine the ranking of risk signiticant failure modes. A list of HPCI system failure modes for this system Risk-Based Inspection Guide (System RIG) was developed from a review of BWR plant specilic RIGs.10, and the PRA-Based Team Inspection Methodology!. As presented in Table 4-1, the identitied component failure modes are grouped by risk signiticance that was determined by PRA and other operational considerations. Table $4-2$ provides a summary of the operating experience of the HPCl system for the industry and at the Browns Ferry Nuclear Plant with regard to these risk significant failure modes. Appendices A-1 and A-2 provide more detailed information on the failure events, and selected examples of other PRA-based HPCI system failure modes.

Due to the artifact of modeling. PRAs do not generally provide detailed guidance for inspection activities and are less helpful in the determination of specifie fitilure modes or root caluses of equipment failures. This makes it necessary for an inspector to draw on his experience, and a variety of information sourees such as the plant operating history, Licensec Event Reports (LERs), NRC Bulletins, Information Notices and Generic Lellers, INPO documents, and vendor information to conduct an inspection of the PRA-prioritized items. Information useful for prioritization of inspection efforts has been obtained by review of HPCI system operating experience at the Browns Ferry Nuclear Plant and other BWR plants to aggregate observed problems to the categories of PRA-derived failure modes. This information is used to develop the system walkdown checklist of risk signiticant components for inspection emphasis. The system walkdown checklist for use by the inspector(s) is presented in the next section. The results of the $\mathrm{HHCl}$ operating experience review are discussed in Section 6 with illustrative examples to show applicability to the PRA-based failure modes.

The survey of HPCI-related LERs generated at the Browns Forry Nuclear Plant included all LERs documented between 1980 and 1992 for the 3 plant units. It is noted that Browns Ferry Plant Units 1 and 3 were in cold shutdown status throughout most of this period. Thus, the sample of HPCI-related LERs considered in this review was largely based on the operational history of the Browns Ferry Nuclear Plant Unit 2. Because the Browns Ferry Unit 2 was in operation for about half of the evaluation period, this review effectively included the HPCl-related LERs from the other plant units as well. As shown in Table 4-2, the plant specific LER frequency for several $\mathrm{HPCl}$ system failure modes is higher than that observed in the industry-wide survey results. The more frequent $\mathrm{HPCl}$ system failure modes observed at the Browns Ferry Nuclear Plant were:

1. HPCl Pump or Turbine failure to start or run due to:

i) turbinc specd control faults,

ii) inverter trip or failures,

iii) turbine stop valve failures, or

iv) turbine exhaust rupture disk failures, and 


\section{CST/suppression pool switchover logic fitilures.}

The survey of operating experience of the Browns Ferry Plant HPCl system is discussed in Section 6 with the fixus om recurrent problems found in recently issucd L.ERs. 
Tuble 4-1 Summary of PRA-Based Fuilure Modes for the HPCI System

\section{High Risk Importance}

Pump or Turbine Fitils o Stant or Run

System Unavailable Duc to Test or Maintenamer Activities"

Turbine Steam Inlet Valve FCV.73-16 fails to Open

Pump Discharge Valve Fe V.7.3.44 Fitils to Open

\section{Midium Risk Importince}

CSI/Suppression Pool Switchover Logic Fails"

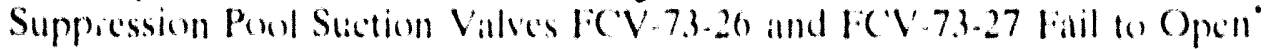

Normally Open Pump Discharge Valve FC V.73-34 Fails Closed or is Plugged

\section{Lower Risk Importinnce}

CST Suction line Chock Valve (

CSt Suction Linc Manual Valve HCV.2.7115 Plugged

Normally Open CST Pump Suction Valve fC C V.73-4t) Fails ('losed or is Plugged

Pump Discharge Check Valec fe V 73-45 fails to Open

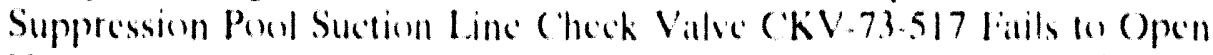

Normally Open Stcam line Containment Isolation Valve I.C V.7.3 2 or

FC. $7.3-3$ Fails Closed"

Steam Line Drain Pot Malfunctions

Turbine Exhaust Linc Faults, including:

- Nermally Open Turbine Exhatuse Valve lic V'.73.64 is Plugged

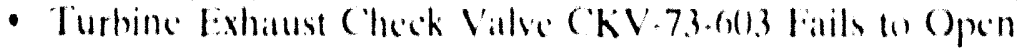

Turbine Exhaust line Vacuum Breatker Valven fiall to Operalte

Fialse High Steam Line Differential Pressure Signal

False High Area Temperatture lablation Signal

Palse law Suction Pressure Jrip

False High Turhine Lxhause Presunte Signal

System Actuation Lagic Fails

Pump Suction Straincr Blockinge

Minimum Flow Valve FCV -73.30 Fails 10 Open. (iven Delatyed Activation of Pump Discharge Valve F('V.73.44.

Indicates a litilure mode found in the Browns ferry plant operating experience review discussed in soction 6 . 


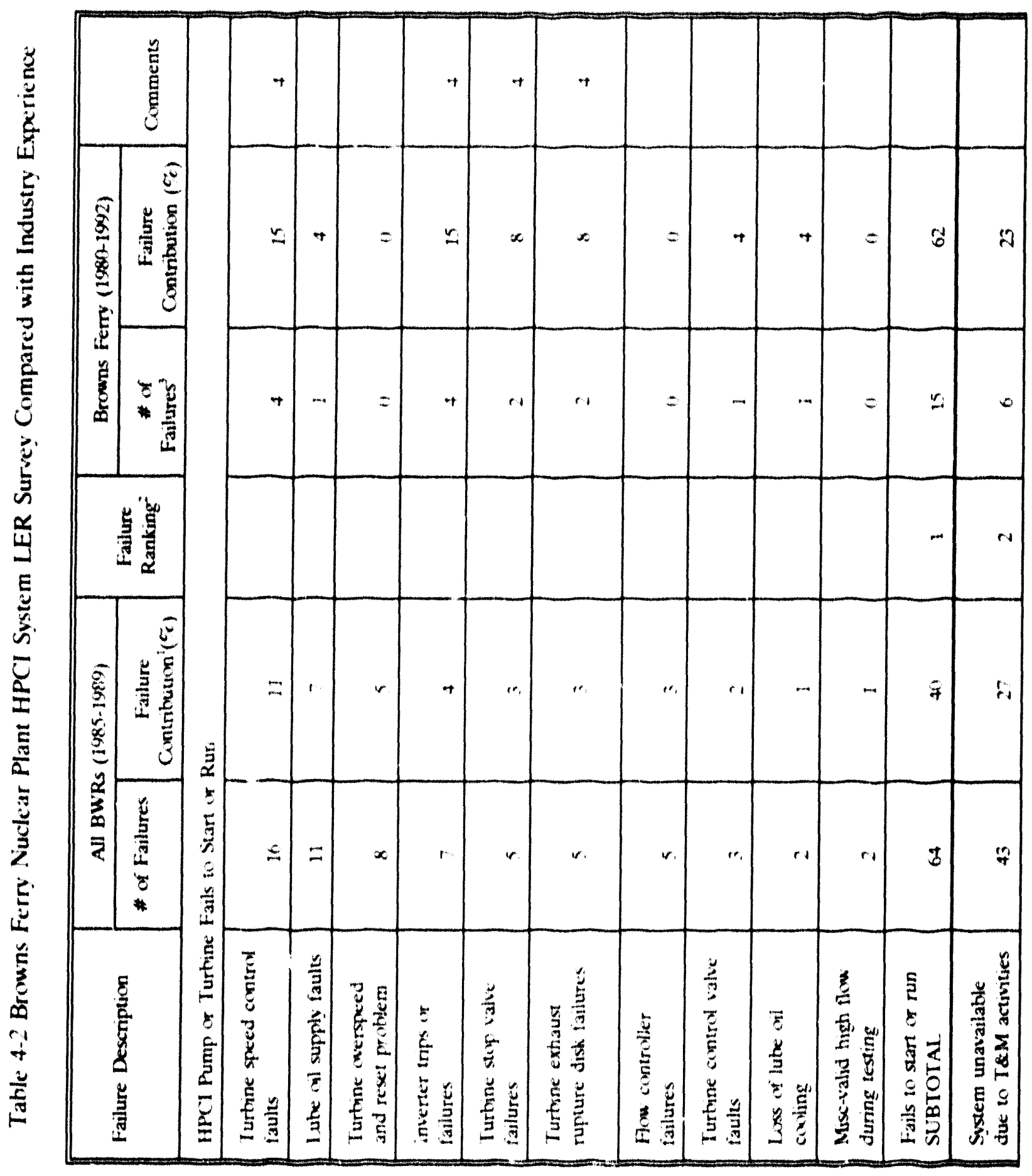




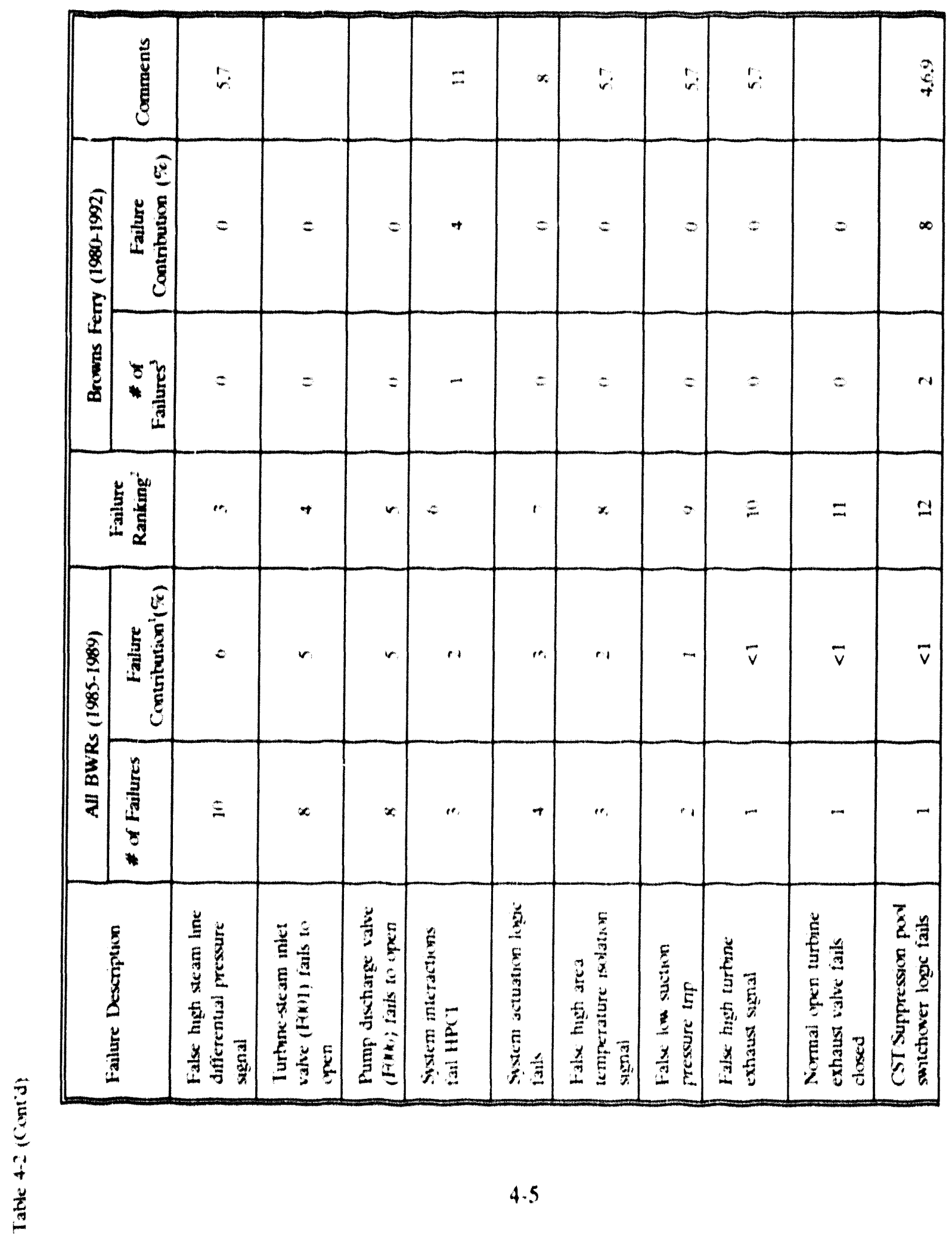




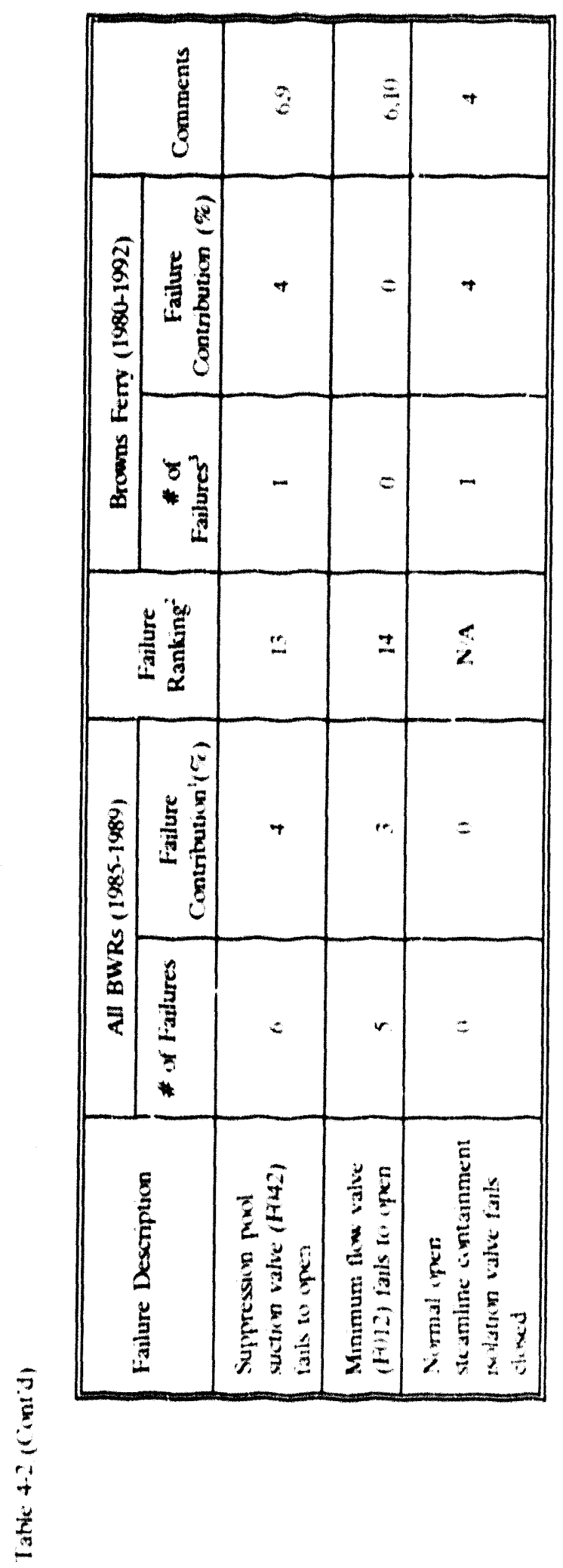




\section{Tuble 4.2 Comments}

1. Failure contribution is expressed as a perentage of all significant HPCl system failures identified by the Operiting Experience Roview.

2. Failure ranking is a subjective prioritization hased on PRA and operational considerations, recovery potential, current accident mamagement philusophy and conditional failures, as applivihle.

3. Significant HPCl system failures alt the Browns Forry Nucleat Plant are determined from the review of all avililible L.ERs (1980 (1) 1992).

4. Although some calution is needed in making this observaltion beciase of the limited plant specific data, this fialure mode secms to comprise a disproportionate fraction of the Browns Ferry HPCl system univialability. This areil is a candidate for enhaneed inspection atlention.

5. Failure importance wals upgraded from the PRA based ranking of Table 4-1.

6. Failure importance was downgraded from the PRA-basced ranking of Table 4-1.

7. HPCI system isolation and trip logies are signiticant contributors to unavailability. The system can be isolated by a single malfunction. yet instrument surveillance intervals can be greater than that reguired for the more reliable actuattion legie.

8. Unlike the system trip and isolation logic, the actuation logic arrangement (one out-of-two ewiec) diminishes the importance of a single instrument fitilure to reliable system operation. At least two low RPV level or two high drywell pressure sensors must fail to result in significant risk As discussed in Section 6, system avialibility is more dependent on the reliability of control power.

9. The latest BWROG Emergency Procedure Gudelincs decmphasize the importance of the suppression pool as an injection source during plant abnormal conditions.

10. Importance of failure mode is conditional on the delityed opening of the pump discharge linc vilve, FCV.73.44.

11. Unlike the rest of the failure modes listed herein, "Systems Interactions" is not a PRAbased failure mode. Il was identified as at signiticant failure mechanism during the operatting experionec review and is discussed in Section 6. 


\section{HPCI SYSTEM WALKDOWN CIIECKLIST BY RISK IMPOR'TANCE}

Table 5.1 presents the HPCI system walkdown checklist for use by the inspecter(s). This information allows the inspecter fo fiesus the inspection efforts on components that are important to system availability and operability. Equipment locations and power sources are identified to assist in the assessment of this system. The risk significinec of the various components identified in this checklist have heen determined by information in PRAs and other operational considerations. 
Table 5-1 Browns Ferry Plant HPCI System Walkdown Checklist

\begin{tabular}{|c|c|c|c|c|c|}
\hline Description & ID NO. & Location & $\begin{array}{l}\text { Power Source } \\
\text { and Location }\end{array}$ & $\begin{array}{l}\text { Standby } \\
\text { Position }\end{array}$ & $\begin{array}{l}\text { Actual } \\
\text { Position }\end{array}$ \\
\hline \multicolumn{6}{|c|}{ A. Components of High Risk Significance } \\
\hline $\begin{array}{l}\text { Turbine Steam } \\
\text { Isolation Valve }\end{array}$ & $\begin{array}{l}\text { FCV-73- } \\
16\end{array}$ & $\begin{array}{l}\text { HPCI Room } \\
\text { Reactor Bldg, } \\
\text { Elev. 519' }\end{array}$ & $\begin{array}{l}250 \text { VDC RMOV } \\
\text { Board A, } \\
\text { Panel/Breaker 3D }\end{array}$ & Closed & \\
\hline $\begin{array}{l}\text { Inboard Steam } \\
\text { Isolation Valve }\end{array}$ & FCV - $73-2$ & Drywell & $\begin{array}{l}\text { 480VDC RMOV } \\
\text { Board A, } \\
\text { Panel/Breaker 17E }\end{array}$ & Open & \\
\hline $\begin{array}{l}\text { Outboard Steam } \\
\text { Isolation Valve }\end{array}$ & FCV-73-3 & $\begin{array}{l}\text { HPCI Room- } \\
\text { Elev. 551' }\end{array}$ & $\begin{array}{l}250 \text { VDC RMOV } \\
\text { Board A, } \\
\text { Pancl/Breaker } \\
\text { 11D1 } \\
\end{array}$ & Open & \\
\hline $\begin{array}{l}\text { Pump Inboard } \\
\text { Discharge Valve }\end{array}$ & $\begin{array}{l}\text { FCV-73- } \\
44\end{array}$ & $\begin{array}{l}\text { HPCI Room- } \\
\text { Elev. } 519^{\prime}\end{array}$ & $\begin{array}{l}250 \text { VDC RMOV } \\
\text { Board A, } \\
\text { Panel/Breaker 7A }\end{array}$ & Closed & \\
\hline \multicolumn{6}{|c|}{ B. Components of Medium Risk Significance } \\
\hline $\begin{array}{l}\text { CST Suction } \\
\text { Isolation Valve }\end{array}$ & $\begin{array}{l}\text { FCV-73- } \\
40\end{array}$ & $\begin{array}{l}\text { HPCI Room- } \\
\text { Elev. } 519^{\prime}\end{array}$ & $\begin{array}{l}250 \text { VDC RMOV } \\
\text { Board A, } \\
\text { Panel/Breaker } \\
\text { 1D2 }\end{array}$ & Open & \\
\hline $\begin{array}{l}\text { Pump Outboard } \\
\text { Discharge Valve }\end{array}$ & $\begin{array}{l}\text { FCV-73- } \\
34\end{array}$ & $\begin{array}{l}\text { HPCI Room- } \\
\text { Elev. 519' }\end{array}$ & $\begin{array}{l}250 \text { VDC RMOV } \\
\text { Board A, } \\
\text { Panel/Breaker 5A }\end{array}$ & Open & \\
\hline $\begin{array}{l}\text { Pump Minimum } \\
\text { Flow Valve }\end{array}$ & $\begin{array}{l}\text { FCV-73- } \\
30\end{array}$ & $\begin{array}{l}\text { HPCI Room- } \\
\text { Elev. 519' }\end{array}$ & $\begin{array}{l}250 \text { VDC RMOV } \\
\text { Board A, } \\
\text { Panel/Breaker 8D }\end{array}$ & Closed & \\
\hline $\begin{array}{l}\text { Pump Suction } \\
\text { From } \\
\text { Suppression } \\
\text { Pool (2 Valves) } \\
\end{array}$ & $\begin{array}{l}\text { FCV-73- } \\
26 \text { and } \\
\text { FCV-73- } \\
27\end{array}$ & $\begin{array}{l}\text { HPCI Room- } \\
\text { Elev. 519' }\end{array}$ & $\begin{array}{l}250 \text { VDC RMOV } \\
\text { Board A, } \\
\text { Panel/Breaker } 4 D \\
\text { and 9D } \\
\end{array}$ & Closed & \\
\hline $\begin{array}{l}\text { Turbine Exhaust } \\
\text { Valve to } \\
\text { Suppression } \\
\text { Pool }\end{array}$ & $\begin{array}{l}\mathrm{HCV}-73- \\
23\end{array}$ & $\begin{array}{l}\text { Torus Room- } \\
\text { Elev. } 519^{\prime}\end{array}$ & NA & Open & \\
\hline
\end{tabular}


Table 5-1 (Cont'd)

\begin{tabular}{|c|c|c|c|c|c|}
\hline Description & ID NO. & Location & $\begin{array}{l}\text { Power Source } \\
\text { and Location }\end{array}$ & $\begin{array}{l}\text { Stundby } \\
\text { Position }\end{array}$ & $\begin{array}{l}\text { Actual } \\
\text { Position }\end{array}$ \\
\hline $\begin{array}{l}\text { Full Flow Test } \\
\text { Valves to CST }\end{array}$ & $\begin{array}{l}\text { FCV }-73- \\
35 \text { and } \\
\text { FCV-73- } \\
36\end{array}$ & $\begin{array}{l}\text { HPCI Room- } \\
\text { Elev. } 519^{\prime} \text { and } \\
541^{\prime}\end{array}$ & $\begin{array}{l}\text { 250 VDC RMOV } \\
\text { Board A, } \\
\text { Pancl/Breaker } 6 \mathrm{~A} \\
\text { and Board B, } \\
\text { Pancl/Breaker } 4 \mathrm{~A}\end{array}$ & Closed & \\
\hline
\end{tabular}

Notes: 1. All circuit breakers should be in the closed (ON) position.

2. These valves are included in the ASME Inservice Testing (IST) Program.

Additionally, some of these valves are required to be tested under the guidanee of Generic Letter 89.10. Results of IST and Generic Letter 89-10 testing requirements may be reviewed to assure the adequacy of operational readiness of these valves. 


\section{OPERATING EXPERIENCE REVIEW}

As previously stated. an operating experience review was performed to evaluate recent industry-wide operating experience of the HPCI system in BWR plants and categoize the various observed problems with PRA derived failure modes. Approximately 200 Licensee Event Reports (LERs) describing HPCI system failures that occurred in the period between 1985 to 1992 were reviewed for applicability to the PRA failure modes for the HPCI system. Sixty-two LERs did not have a corresponding failure mode. These LERs generally documented sucessful system challenges, administrative deviations, or seismic/equipment qualification concerns. The remaining 140 LERs documented $159 \mathrm{HPCI}$ system faults or degradations. As presented in Table 6-1, these failures have been categorized by PRA failure modes to provide a relative indication of the contribution to all HPCI system faults. Each of the 14 PRA-based failure modes that has corresponding industry failures is discussed below. Selected LERs identified during the operating experience review are summarized to illustrate typical failure mechanisms and potential corrective actions. Where applicable, other sources of background information including NRC IE Bulletins, Information Notices, Inspection Reports, NUREGs, and AEOD Repoits are cited. The Browns Ferry Nuclear (BFN) Plant HPCI system operating experience over the plant life is also integrated into the discussion of each $\mathrm{HPCl}$ failure mode.

Tuble 6-1

\section{HPCI Fuilure Summary}

Failure

Number
Description

Pump or Turbine Fails to Start or Run

1

2

3 Activitios

False High Steam Line Differential Pressure

Isolation Signal

4

5

6

7

8

9

False Low Suction Pressure Trip

False High Turbine Exhaust Signal

\section{Total Fuilures* \\ HPCI Fuilure Contribution (\%)}

\section{0

27

43

10

8

8

3

False High Area Temperature Isolation Signal

64

* Identified during the HPCI System Operating Experience Review which examined HPCI LERs from 1985 to mid 1992.

** Non PRA-derived failure mode; operating experience is discussed in Section 6. 
The search of LERs generated from the Browns Ferry Nuclear Plant Units 1, 2, and 3 (Docket numbers 50-259, 260, and 296, respectively) was conducted for the period between 1980) and 1992 , and 67 LERs were found to be related to HPCI system problems. It is noted that the BFN plant units were in operation for about half of the evaluation period and thus, this evaluation effectively considers the operating experience of the BFN station as if it was a single nuclear power plant. Out of the $67 \mathrm{HPCl}$ system-related LERs reviewed for the BFN plant, 26 LERs were found to fall within the set of PRA-based failure modes. The breakdown of the 26 L.ERs within each category of PRA-based tailure modes is: 15 LERs were related to HPCI pump or turbine failures to start or run, six LERs were related to HPCI system unavailability due to testing and maintenance activities, two LERs described CST/suppression pool switchover logic failures, and each of the remaining LERs were related to events involving the suppression pool suction valve failure to open, steam line outboard isolation valve failing closed, or a system interactions problem failing the $\mathrm{HPCl}$ system. Based on the LER survey, specific component finilures of importance that require attention at the BFN plant are turbine speed control fiults, inverter failures, turbine stop valve failures, turbine exhaust rupture disk failures, and condensate storage tank leve! switch failures.

The information compiled in this section should be useful in more detailed reviews of the $\mathrm{HPCl}$ system, rather than routine operational checks. It may be used during programmatic inspections (such as maintenance program reviews) or in reactive inspections of HPCI system failures.

Illustrative examples of corresponding industry failures for the first failure mode, "HPCI Pump or Turbine Fails to Start or Run," are presented in Table A-I along with details of the root cause, method of detection, corrective actions, and potential inspection areas that could identify and prevent similar problems. The examples of industry failures for the other PRA failure modes are discussed in Table A-2. The text provides additional information on the distribution of failure events within a particular failure mode.

\subsection{HPCI System Failure Modes}

\section{HPCI Fuilure No. 1. Pump or Turbine Fails to Start or Run}

The major contributor to HPCI system unavailability, both from risk and operational considerations, is the failure of the turbine driven pump to start or continue running. This failure mode includes dependent failures as a result of subtle interactions between various subsystems and components and thus, root cause analysis and component repair becomes a complex task. The concern on system interaction problems has been reflected in BWR plant PRAs by the assessment of various subsystem, or support system failures that cause this failure of the pump or turbine to start or run. However. the uncertainties associated with identifying system interaction probalems have resulted in some confusion in the application of PRA insights for inspection activities. For the purposes of this study, this failure has been detined as the loss of functional capability of those components that directly support the operation of the pump or turbine. The basic event deseribing "HPCI Pump or Turbine Fails to Start or Run" accounted for 64 failures or $41 \%$ of the HPCI system faults in the industry-wide operating experience review. Table 6.2 shows the subcategories of failure mechanisms that maly result in Failure No.l, and the number of events in each subcategory. 
Tuble 6-2

HPCl Pump Turbine Fuils to Start or Run - Failure Subeategories

\section{Sub-cutegory Description}

A. Turbine speed control faults, including

EG-M control box

Motor speed changer (EG-R actuator remote servo)

Resistor box

Ramp generator/signal converter box

Magnetic speed pickup cable

Speed control potentiometer

B. Lube oil supply faults

C. Turbine overspeed and auto reset problems

D. Inverter trips or failures

E. Turbine stop valve failures

F. Turbine exhaust rupture disk failures

G. Flow controller failures

H. Turbine control valve faults

I. Loss of lube oil cooling

J. Miscellaneous: Valid high steam flow during testing

TOTAL
LER Fuilures

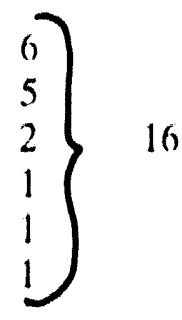

16

11

8

7

5

5

5

3

2

2

$\overline{64}$

\section{A. Turbine Speed Control Faults}

The turbine speed is controlled automatically by a control system consisting of a flow controller and an electro-hydraulic turbine governor. As in most other plants, the BFN plant HPCI pump turbine has a Woodward governor control system. The turbine governor system receives the flow controller signal input and processes the electrical signal to effect hydraulicmechanical motion to position the governor (control) valve. The system has a "ramp" generator which upon turbine start, will control the acceleration rate up to a speed relative to the flow controller output demand signal. The ramp generator is part of the ramp generator and sigıal converter (RGSC) box at the BFN plant and the "ramp" rate is adjustable.

Turbine speed control faults are a major contributor to the pump failure to start. The sixteen failures identified in the industry-wide LER survey include:

- six electro-mechanical governor (EGM) control box faults,

- two dropping resistor assembly (resistor box) failures,

- one ramp generator/signal converter box failure,

- one magnetic speed pickup cable malfunction,

- one speed control potentiometer problem, and

- five motor speed changer/electro-mechanical hydraulic (EG-R) actuator faults. 
The LER survey for the BFN plant identified 4 LERs related to turbine speed entrol faults. In the tirst event (LER 259/8(1)-(1)79), an electrical ground occurred on the EGR actuator as a result of corrosion between the EGR actuator eonnector and connector pins. The electrical ground cilused failure of the EGM output transistors OY \& Q10, and resulted in turbine specd control problems. The second event (LER 260/83-()(19) was related to a HPCI pump turhine failure resulting from the erratic performance of the thow controller which was caused by trapped air in the hydraulic oil control system tollowing maintenance repair work. In the third event (LER 26(1)/84-(1)3), the operator was unable to bring the speed of the HPCI turbine down to the required 2.400 RPM because of an erratic ramp generator/signal converter hox adjustment. The fourth cevent (LER 260/85-(1)15) was related to a design deficieney in the resistor box. A special test showed that $A C$ output voltage from the dropping resister box wats insufficient when its input voltage was at the design minimum. The resistor box was moditied to ensure that the EGM control box would receive the required $A C$ voltage signal under worst casce conditions.

As a result of the observed problems, significant hardware modifications of the HPCI system have been made att the BFN plant unit 2 to reduce the potential oceurrence of turbine speed control faults. The HPCl governor control system hats been redesigned and upgraded with new components, and the EGM contrel panel has been relocitted from the lurbine skid to the HPCl room wall to eliminate the vibrattion effects of the skid environment. A new overspeed test controller in place of the original bias speed selting potentiometer, and new and more reliable $24 / 48 \mathrm{Vde}$ power supplies for the control system were also installed. Other specitic upgrades included the replacement of the RSGC box. EGM controller, speed sensor and cable assembly with new components, replacement of existing copper piping for auxiliary oil supply with stainless sted, and addition of seismic restraints to the turbine skid piping. In addition to hardware improvements, the system surveillances include functional testing of the EG-R assembly on a quarterly basis during the performance of the HPCI system thow rate test to assure reliable operation. Monthly inspections to verify the correctness of system oil pressures require the auxiliary oil pump to be cycled, and this operation results in cycling of the turbine stop valve and turbine control valve which further verities the operability of the EG-R assembly. Furthermore, a tiered approach in the

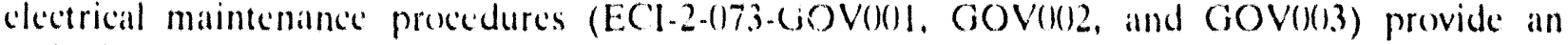
anditable process of governor control system checks and calibration.

The HPCl turbine speed control is a very complex area that requires specialized attention. EG-R actuater failures may increase ats the HPCI system and speed control subsystem ages.

Thus, the inspector(s) should contirm that there is adeguatte oversight on the modifications, operations, maintenance and surveillanes of the turbinc speed control subsystem to ensure functional adequacy of the HPCI system.

\section{B. Lube Oil Supply Finults}

This failure mode subcaltegory consists of cleven failures to provide sufficient lubricating oil to turbine components. As presented in Table A-1, most of the failure events are related to the auxiliary oil pump (AOP) faults which include two bearing fallures and tive auxiliary oil pump pressure switch faults. Three other events involving low bearing oil pressure events were attributed to valve mispositioning and oil contamination. 
There was one LER cvent at the BFN plant describing a lube oil supply fault. In this event (LER 260/82-(0)16), the HPCI lubricating oil reservoir was found to be almost empty because the reservoir drain valve wass sufficiently open to drain most of the reservoir contents. This condition rendered the $\mathrm{HPCl}$ system inoperable. The caluse of the problem was attributed to personnel error.

Current surveillane practices at the BFN plant preclude the oceurrence of such an event. Daily shift walkthrough inspections require plant personnol to verify that the lube oil reservoir is not depleted through visual observation. Furthermore, the HPCl lube oil reservoir is sampled once a month to assure contamination free oil in the lube oil reservoir supply. If degraded oil samples are found, the oil is filtered to return it within specitications.

\section{Turbine Overspeced and Auto Reset Problems}

The mechanical overspeed trip function is set at 125 pereent of the rated turbine speed. The displacement of the emergency governor weight lifts a ball tappet which displaces a piston that allows oil to be dumped through a port from the oil operated turbine stop valve 2-FCV-73-18. This allows the spring force acting on the piston inside the stop valve oil cylinder to close the stop valve. The overspeed hydraulic device is capable of antomatic reset after a preset time delay.

In the industry-wide survey, overspeed and auto reset problems were found to have contributed to eight fitilures in the turbine driven pump failure category. Although the LER search did not identify any event involving turbine overspeed and auto reset problems at the BFN plant, the licensec personnel should be cognizant of the potential problems of turbine overspeed trips resulting in "lockout" conditions. Additional sourees of information on lurbine overspeed trips are NRC Information Notice 86-14," 86-14 Supplements 1 and 2," and AEOD Case Study Report $\mathrm{C} 6(1) 2 .^{13}$

\section{HPCI Inverter Trips ar Failures}

Control power supply for the BFN plant HPCI system was originally provided by the HPCl "Topaz" inverter that was powered from a $125 \mathrm{VDC}$ hus. As a result of design modifications to have more reliable control power supplies for the HPCl system, the HPCI inverter was replaced with a direct connection to the Division II 120 Vale Uninterruptible Power Supply (UPS) system used by the analong trip system. The design change also added new 48 Vde power supplies to provide reliable DC power to the governor control system. The present design of the HPCI system also include loss of power annunciator alarms in the main control room (MCR) for all ?:PCl control power supplies.

The LER survey for the BFN plant identitied 4 LERs related to problems associated with the old "Topaz" inverters. In three failure events (L.ERs 259/85-(0)6, 26(1)/8.3-(028 and 260/8.3-(1)34), the HPCI system was dedared inoperable ats a result of blown inverter fuses. The fourth event (LER 260/83-()46) was related to a fialure of the inverter transformer which resulted in the HPCI system being declared inoperable. Although the HPCl inverter has been replaced with a direct connection to the Division II 120 Vac UPS system in the present design of the HPCI system, the licensec personnel should be cognizant of the impact of fuse problems on the reliability of eontrol power supplies. An extensive fusc control program has been implemented at the BFN plant to control activities related to fuses. This program includes fuse coordination calculations for safety-related power supplies, updated luse drawings, and new identitication documentation for safely-related 
fuses. Additional informattion on potential problems due to inadeyuate fuse control programs is provided in NRC Information Notice 91.51."

\section{E. Turbine Ston Vilue Failures}

The turbine stop valve FCV -73-18 is lecited in the steam supply line near to the inlet connection of the turbine. The primary function of the value is to close quickly and stop the flow of steam to the turbine when appropriately signaled. A secondary function of this hydraulically operated valve is to open slowly to provide a controlled rate of admission of steam to the turbine and its governing valve.

Review of the industry-wide operating experience indieated that there were 5 failures of the turbine stop valve. Since 1980, two reportible events involving HPCl turbine stop valve failures heve oceurred at the BFN plant. In the first event (LER 259/8()-(126), the HPCI turbine stop valve 1.FCV-73-18 would not open completely hesiatuse of a worn out mechanical overspeed trip piston. In the second event (LER 260/82-(1)2), the HPCl turbine stop valve 2-FCV-73-18 would not stay open because the Leespring did not compress adequately to allow the trip mechanism to remain in the reset position.

As part of a reliability-centered maintenance (RCM) program for the HPCl system at the BFN plant, the overspeed trip tappet is scheduled for mainfenance inspections at every refueling outage. Based on vendor information (GE Scrvices Information Lelter) which identitied potential binding problems, the tappet assembly is replaced with a new component design with improved performance reliability. The vendor has also recently verified that the turbine stop valve has the correct spring constant in the pilot valve spring. In addition, uperability of the turbine stop valve is veritied on a yuarterly basis during the performanee of the HPCI system flow rate surveillance test. During this test, the specified opening times of the turbine stop valve are verified and anomilous oferation of the valve is noted for corrective actions.

\section{F. Turbine Exhaust Runture Disk Failures}

The HPCl pump turbine has a set of two mechanical rupture diaphragms in series which protect the exhaust piping and turbine casing from overpressure conditions. When the inner disk ruptures, pressure switches initiate turbine rrip and HPCI isolation signals. Lew pressure steam flows past the ruptured diaphragm through a restriction orifice directly inte the HPCI room. Rupture of the second disk would vent the turhine exhaust into the HPCI pump room without flow restriction. The nominal rupture pressure is approximately $175 \mathrm{psig.}$

Since 1980, there were two LER events related to turbine exhaust rupture disk failures at the BFN plant. In the first event (LER 260/80-()32), failure of the teflon sheet portion of a rupture disc resulted in a $\mathrm{HPCl}$ turbine trip. The second event (LER 260)/83-(074) was related to the rupture of : turbine exhaust rupture disk which rendered the HPCI sysiem inoperable soon after system inciation following a reactor scram.

In the IREP PRA study of the BFN plant, the dominant contributors to HPCl system unavailability were rupture disk failures. These failures accounted for about 31 and $45 \%$ of $\mathrm{HPCI}$ system unavailability considered in the LOCA and transient initiated sequenees, respectively. Thus, the installation of rupture disks with a structural backing (or the periodic inspection of the older 
type design of disk) was recommended to prevent these cyclic fatigue failures. Presently, the BFN plant utilizes "Fike Metal Product" rupture dises to ensure that the turbine casing does not experience overpressurization during a transient event. These rupture dises are replaced at every tive years to ensure satisfictory operation. Furthermore, design modifications and installation of new governor control system components eliminate governor control system startup transicnts which had caused the rupture disc finilures.

\section{G. Elow Controller Fiilures}

The flow controller 2-FIC-73-33 in conjunction with the clectro-hydraulic turbine gevernor controls turhine specd and pump flow rate. The tlow controller senses pump discharge flow and outputs a 4 to 20 milliamp signal to the turbine governor to maintain a constant pump discharge flow rale over the pressure range of operation.

There were no L.ER events involving llow controller fialures at the BFN plant.

\section{H. Turbins Control Vilve Fuules}

In the industry-wide operating experience review, three lurbine control valve fault events were attributed to different root caluses. At the BFN plant, one LER event (LER 260/83-(128) described the HPCl turbine control valve finilure to open due to a misadjusted rod. Potential failures of the turbine control valve can oceur as a result of broken lifting beam bolts or broken steam control valve pilot (or poppet). NRC AEOD Study Report T906" provides additional information on contributors of the bolt finilures of HPCl Terry turbines. Presently, mechanical maintenance procedures (MMI-23) at the BFN plant include yuality control inspections of all $\mathrm{HPCl}$ system maintenanee work to preslude the oceurrence of turbine control valve finults. In particular. these procedures have a $Q C^{\prime}$ signoff for veritication of the sover nut lorquing after maintenance on the turbine control valve.

\section{Loss of Lubu Oil Cooling}

The loss of lube oil cooling can be caused by faults in the cooling water lines to and from the cooler, cooler leakange, or tlow blockange. A prolonged loss of lube oil cooling can lead to turbine bearing failure.

In the LER survey of the BFN plant, there was one event (LER 259/8()-(0.55) in which the pressure control valve 1.PCV-73-43 was found to be stuck closed due to a loose valve guide and this resulted in the loss of lube oil cooling. Presently, the HPCl system thow rate surveillance test procedure requires that all turbine and pump skid temperatures to be recorded during the test performance for subsequent review to ensure adequate cooling is available to all system components including the pressure control valves under normal operating conditions.

\section{J. Miscellaneous ... Valid High Steam Flow During Testing}

Another petential system failure involves the practice of running the auxiliary oil pump to lubricate the turbine bearings or to elear an electrical ground in the system. In the Monticello plant, this practice was used in attempts to clear an electrical ground in the electro-hydraulic governor. A system test was initiated to confirm HPCI system operability when the electrical fault 


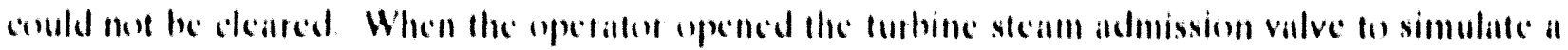
cold quick statt. the system isolatted on high stealln flow. The operation of the aluxiliary oil pump cilused the hydrablically operated turbine step valve to move from its full clesed to its full upen

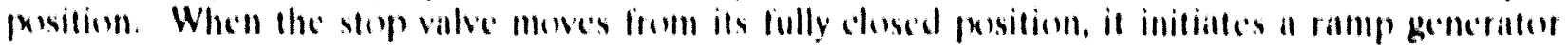
response that provides the flow control signal to the turbine steam admission valve and thus.

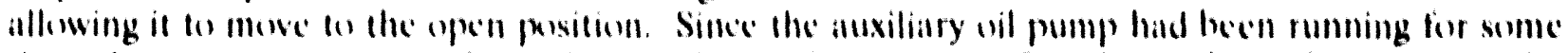
lime, the ramp generater had limed ont and a maximum steam llow demand signal was sent fo the control valve. This prevented the turhine steam admission valve from restricting steam flow as it mormally would during a turbins stant, and this condition results in high stom flow and a valid system iscolittion.

Common practice in sume plants indude running the anxiliary pump periodically on keop the

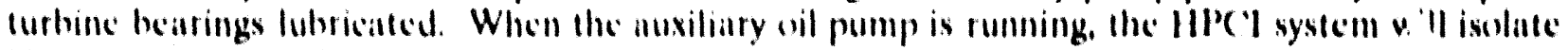
if an alutemattic intiation signal is received alt any time aller the ramp generator has timed cut,

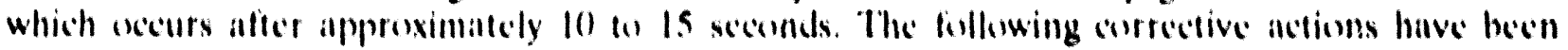
taken at the Menticello plant to indatress the problem:

- A moditication has heed approved that will climinate ramp generator initiation while the anxiliary oil pump is running unless a valid initiation signal oceurs.

- The HPCl system operating procedures have been revised fo indude contion suatements addressing system innerability when the anxiliary oil pump is running.

- The operating procedures utilized 10 verity system operahility have heen revised in

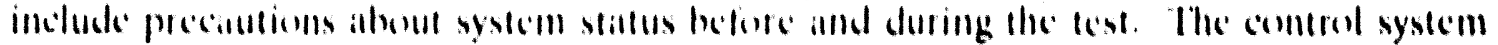

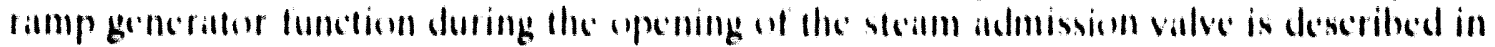
these prosedures.

In summary, this is a significant collecrn because a commong plant practice has the pelfential

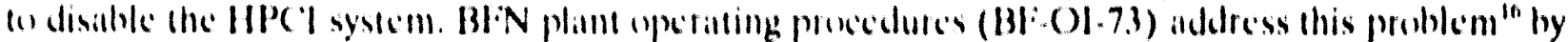

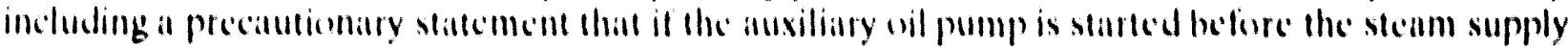

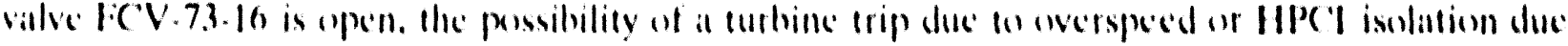
fo excessive steilm llow cexists.

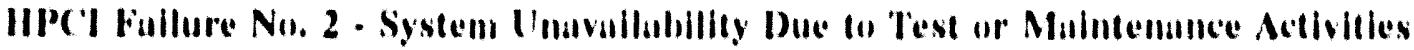

In a probihilistic risk assesument (PRA), estimates of system unavailability are determinced

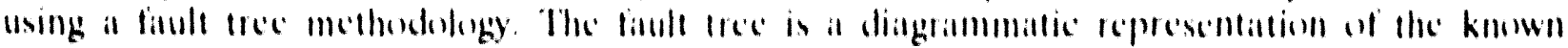

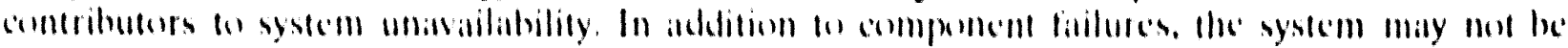

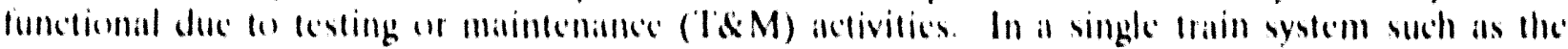

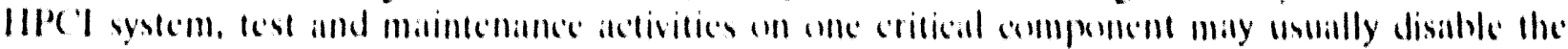

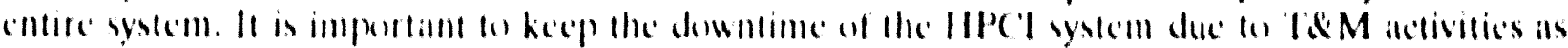

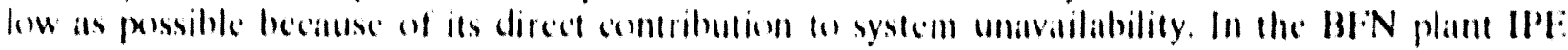

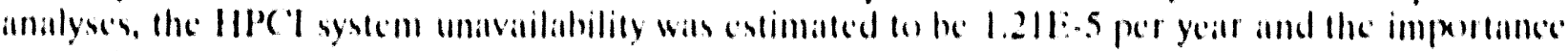

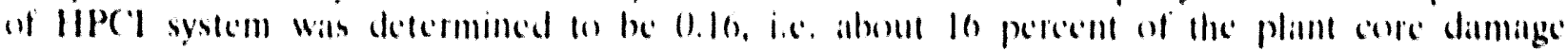

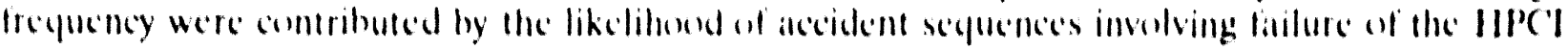

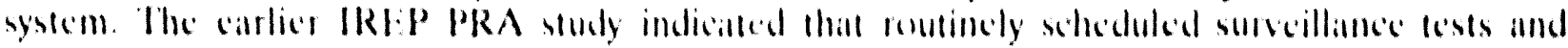

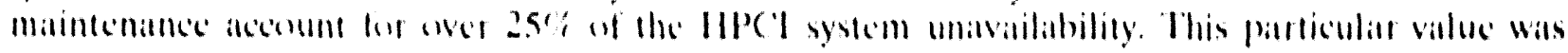




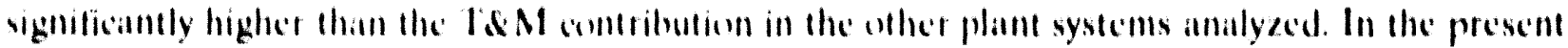

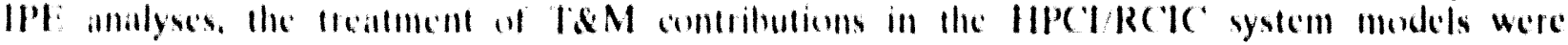
conservative in that meredit was laken for the simultancous performance of lid M prosedures on

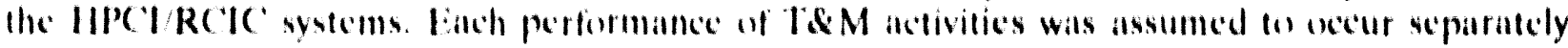

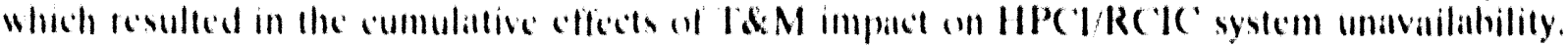

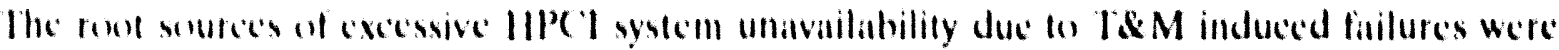
cximined as part of this eperating experience review. In the industry-wide survey, fierty-fhree

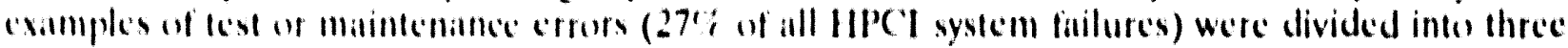

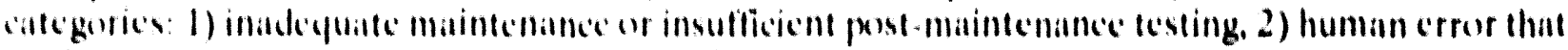
imidvertently disibles the IIPCI system, and 3) system inadvertently disabled during lesting activity. Inadequate maintenames or insulficient post maintenance lesting resulted in 22 HPCl system linlures. The problems included value picking leaks, misidjusted lorgue switsh settings. miscialibrations of a steam line differential pressure instrument and an E(iR actuatere, improper connection of a gland exhanster drain line lo lle bube (high pressure) side of the gland scal condenser, system andjustment without a retest, and a tigg left in the furbine sump which disabled the shaft driven oil pump?

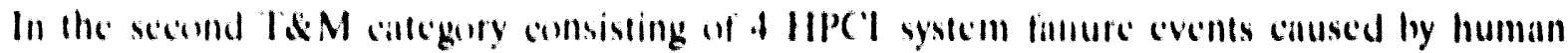

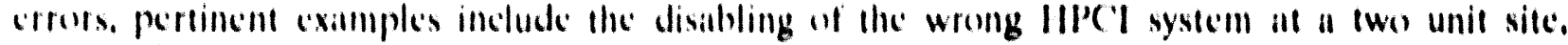
mistakenly disibling the anxiliary oil pump due to a smoke ador in the HPCl room, and valving errors which subseguently colused a low pump suction erip or inadeguate lube oil pressure at the

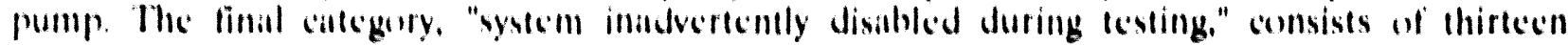
persomel errors that temperatrily disabled the IIPCI system. These incidents indede steam line

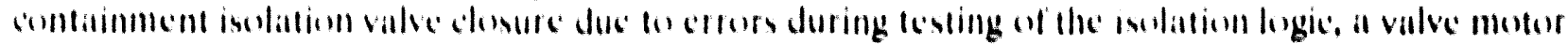

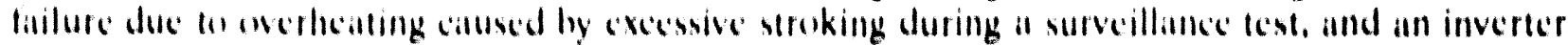

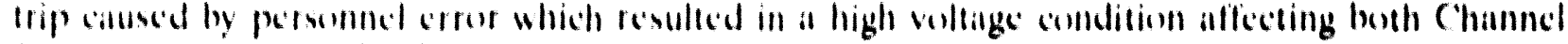

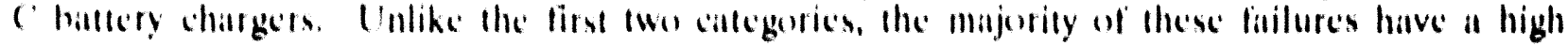
probability of resonery.

The search of HPC' system-relatted I.IERs identitied o L.ERs getlerated at the BFN plant that resulted from events in which the IIPCI system was unavailable due to maintenance and testing activitice. In most af these events, the HPCl system was rendered inoperable during the performance of surveillance lests. One cvellt (I.K:R 259/82.032) occurred during lesting activities

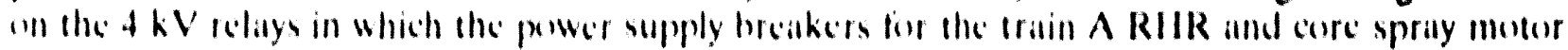
driven pumps were racked oul. and this pesuled in the inoperability of both pumps and the IIPCI system. Procedural deficioncy and lack of communication were the catuses of simulaneous

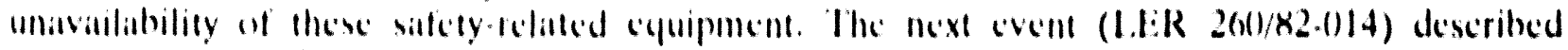
surveillances mot being perfurmed dac lo personnel error after the IIPCl system was made

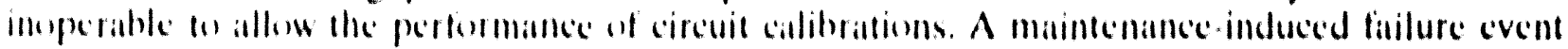

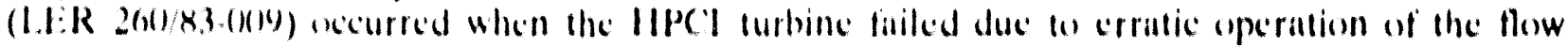
controller which was calused by trapped air in the hydraulic oil control system following

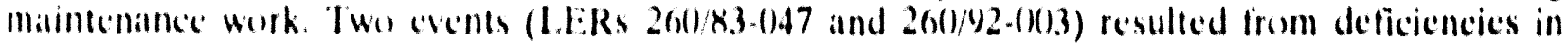
installiation procedures. In the tirst case (I.I:R 83.(147), a wiring corror resulted in the HPCI system heing inoperable during a tachometer calibtation activity. The second event (L.ER 92-()(13) was celated on the inadvertemt installation of a test plug that was 120 degrees out of orientation. During

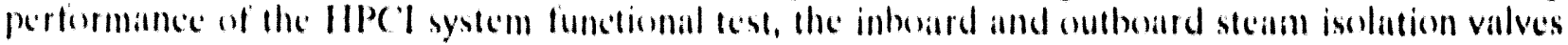

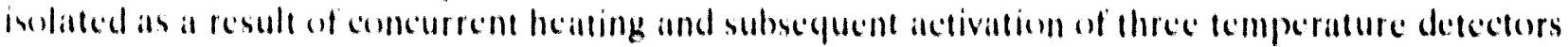




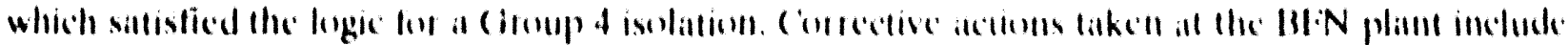

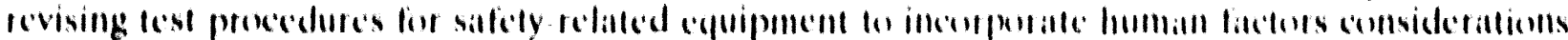

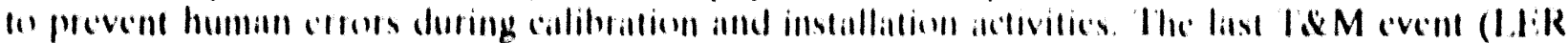

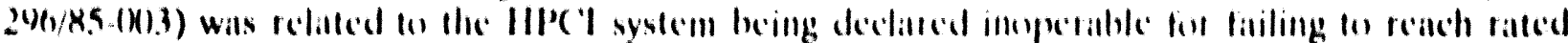

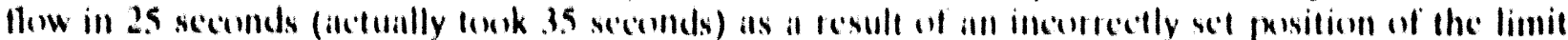

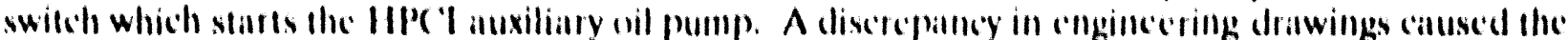

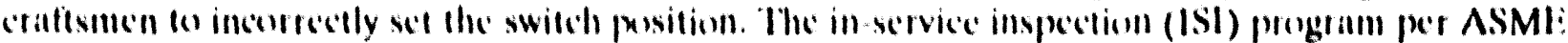

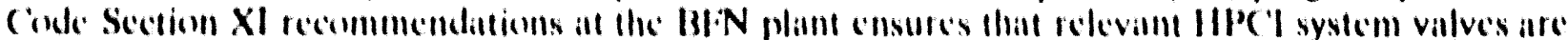

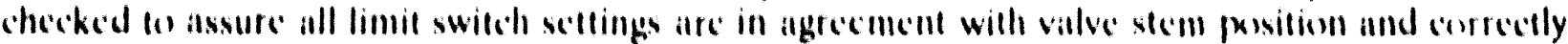

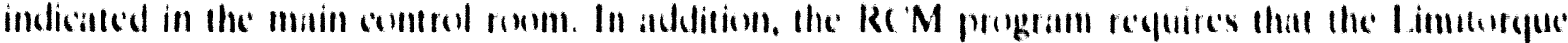

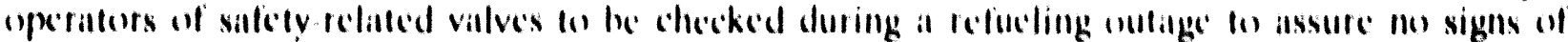
dimllige in the loryese and limit swifches

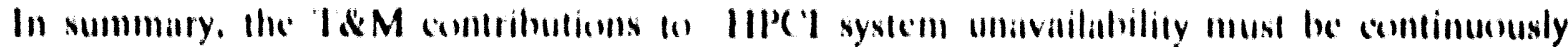

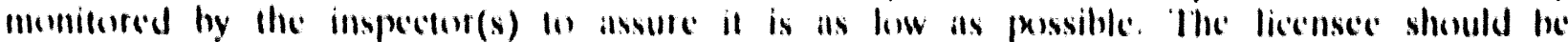

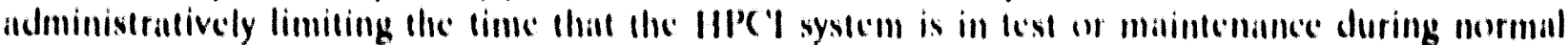

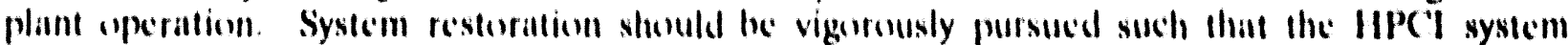
should not be down for days when repair work can be reasonably accomplished in hours. Whenever feasible, portions of the system should be lested during oulanges. In addition, HIPCI

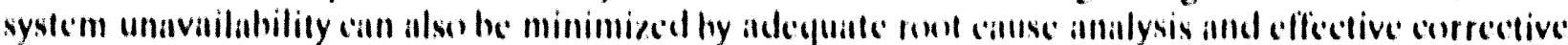

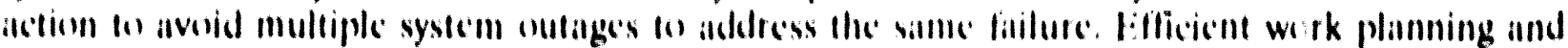
gend engincering practices could also prevent inadvertent on unnecessilty removals from service and system isolations during calibration or surveillaneses. The licensece all the Ble $\mathrm{N}$ plant has set the present unavililabiliy gonl if the (Jnit 2 HPC'I system lo be $0.011 \mathrm{~h}$.

\section{IIP('I Fullure No. a . Fulse Iligh Steum I.lue Dillerentiul Pressure Isolution Signul}

The IIPCI system is constannly monitured for leakange by transmitter deviecs sensing stemm

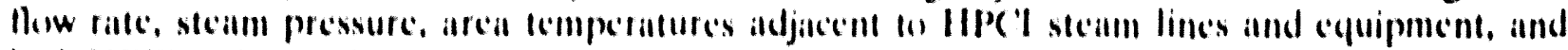

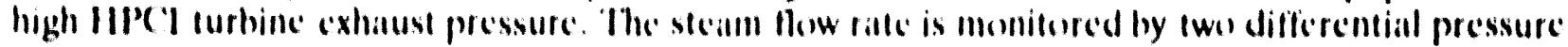
switches lecalted ateross two different shows in the sleam piping inside the primary containment. The llow measurement is derived by measuring differential pressure ateress the inside and outside

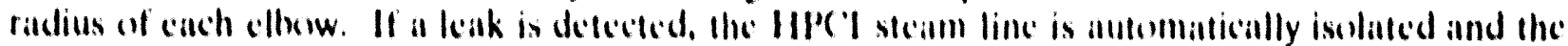
IIPC'I system iscolation is annuncialled in the main control fonmm.

Over the 12 year review period, there were mo l.b:Rs in lhis finilure callegury identified for the BIN pliant.

\section{IIP(I Fuilure No. 4 Turbine Steum Inlet Valve Fe'V-73.16 Fuils to Open}

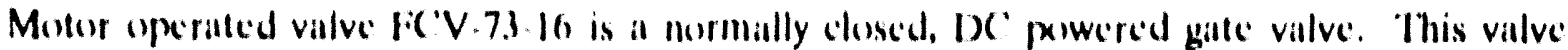
"pens on an automatic or manual initiation signal, provided that the turbine exhaust valve is open, to admit reactor steam up to the lurhine stop valve.

In the industry-wide survey, there were 8 failures of this valve 11 open on demand which comprise 5\% of all HPC'I system finilures. Most of these fitlures were due fo mechanical/thermal 
binding problems due to insufticient stem lubrication, loose torque switch adjustment serews, and inadequate opening torgue capability. There were no L.ERs in this failure contegory identified during the 12 year review period for the BFN plant.

\section{HPCI Fullure No. 5 - Pump Dischurke Vulve FCV.73.44 Fuils to Open}

Motor operated valve FCV.73-44 is a mormally closed, DC powered gate value that is atutomatically opened upon system initiation. The failure of this valve to open disables the HPCI system to inject water into the reactor vessed.

There have heen 8 HPCl pump discharge valve failures documented in the industry-wide operating experience review which account for $5 \%$ of all system failures. Most of the valve failures were generic problems including valve motor failures, a ground of the DC control voltage at the torque switch, and intedequate torque problems due to the use of starting resistors in the valve motor circuitry.

The BFN plant did not have any reportable failures of the HPCI pump discharge valve FCV. 7.3.4t over the 12 year review period.

\section{HPCI Fullure No, 6 - HPCI System Interactions}

Systems interactions refier to unrelated system failures that can disable the HPCI system. Although there is no associalled PRA-based failure ciltegory, the industry-wide uperating experience review identified the following examples of system interactions that disabled the HPCI system:

a) During a tite protection system surveillance test, approximalcly one gallon of water drained onto a battery powered motor control center (MCC) causing a circuit breaker overload trip anc valve inceperability.

b) A cracked thew control value test coupling allowed wilter to be sprayed on a battery powered MCC and resulted in disibling a loss of power monitor on the main steam line drain. The HPCl system was disabled when the MCC was decnergized to allow inspection and drying of the components.

c) An atutumatic sprinkler system in the HPCI room andivated after a system test. The probable caluse was buildup of stean vapor from the leakolf drain system that activated an ionization detector.

d) Sctpoint drift in a Fenwal temperatture switch catused activation of a deluge system during a HPCl lurbine overspeced test.

The LER survey identified one LER event at the BFN plant in which system interactions problems affected HPCI system uperability. In this event (LER 259/82-(132), the prower supply breakers for train A RIIR and core spray pump molors were racked out during the performanec of a surveillance test on the $4 \mathrm{kV}$ relays, and this resulted in both safety-related pumps and the HPCl system inoperable. Procedural deficiency and lack of communication were the causes of the simultancous unavailability of these salety-relatted equipment. Operator training lessons att the BFN plant include examples and descriptions of conseguences of support systems interactions that may 
cause HPCl system inoperahility. The training objectives of providing awareness of system interactions problems are further tested and redofored by simulator training exercises which include proper diagnosis of the effects of the system interactions scenarios.

\section{HPCI Fullure No. 7 - System Actuntion Loglc Fulls}

Startup and operation of the HPCI system is automatically initiated upon detection of either low-low reactor vessel water level $(.45 .0$ inches decreasing) in the reactor vessel or high drywell pressure (2.45 psig, increasing). The HPCl system can also be manually initiated by arming and then depressing the manual initiation switch in the control room.

In the industry-wide survey, there were 4 LERs associated with this finilure mode. These L.ERs illustrate that failure of the HPCI system actuation logic is more likely due to common causes such as the loss of electricial power. Unlike the HPCl system trip logic, the redundancy (one out of two twice design concept) and the diversity (low vessel level/high drywell pressure conditions) of the actuation logic make it less susceptible to the impact of individual sensor failures. Over the 12 year review period, there were no LERs in this failure caltegory identitied for the reactor level and containment pressurization instrumentation of the BFN plant $\mathrm{HPCl}$ system.

\section{HPCI Fullure No. 8 - Fulse IIIgh Aren Temperature Isolution Signal}

The HPCI system is constantly monitored for lenkinge by transmitter devices sensing steam flow rate, steam pressure, and area temperalures adjacent to the steam line and equipment. If a leak is detected, the system is autematically isolated and alarmed in the control room. At the BFN plant Unit 2, the high HPCl system area temperature (indicattive of a stciam leak) is monitored by the temperature switch 2.TS.73-2A.S.

In the industry-wide survey, this caltegory accounted for three HPCl system failures (i.e., about $2 \%$ of all fitilures). During the 12 year review period, there were no LERs identified for the BFN plant that were relitted to false high HPCl system area temperature isolation signals.

\section{HPCl Fuilure No. 9 . False Low Suction Pressure Trips}

The purpese of the low pump suetion pressure trip is to prevent damage to the HPCI pumps duc (o) loss of suction. At the BFN plant Unit 2. the pressure switch 2.PS.73-29 atctuates to caluse the turbine stop valve to close in the event that low HPCI pump suction pressure is sensed.

In the industry-wide survey, there were two occurrences of HPCl pump turbine trips that were attributed to false low suction pressure signals. However, the BFN plant has not experieneed any $\mathrm{HPCl}$ system isolations duc lo false low pump suction pressure trips since 1980.

\section{HPCI Failure No. 10 - False High Turbine Exhaust Pressure Signal}

The high turbine exhaust pressure signal is one of several logic signals from the protective turbine trip circuitry that clese the turbine stop valve and isolitte the HPCI system. The high turbine exhaust pressure signal is generalled by pressure switehes PS-73-22A and PS-73-22B at the BFN plant, and is indicative of a turbine or a control system malfunction. 
There was only one LER in this failure category identified in the industry-wide operating experience review. No LERs related to false high turbine exhaust pressure signals were found for the BFN plant during the review period since 1980.

\section{HPCl Failure No. 11 - Normally Open Turbine Exhaust Valve Fails Closed}

Failure of any one of the turbine exhaust valves to open would cause a turbine trip as a result of a valid high turbine exhaust signal. One BWR plant had experienced a failure of the turbine exhaust line swing check valve. The valve internals were found wedged in a MOV located downstream in the turbine exhaust line and this could potentially cause a turbine trip due to high exhaust pressure. The failure was attributed to the forceful cycling of the swing check discs under low flow conditions. Additional information on the background of such problems is provided in the NRC AEOD Report E402 ${ }^{17}$ and Information Notice $82-26 .{ }^{18}$

At the BFN plant, no LERs were found within the review period that involved failure of normally open turbine exhaust valve HCV-73-23 to close.

\section{HPCI Failure No. 12 - Condensate Storage Tank/Suppression Pool Switchover Logic Fails}

In the standby mode, the HPCI pump suction is normally aligned to the condensate storage tank (CST). Upon a low CST level signal via level switch LS-73-56A and LS-73-56B, or a high suppression pool level signal via level switch LS-73-57A and LS-73-57B, the suppression pool suction valves FCV-73-26 and FCV-73-27 automatically open with subsequent closure of the CST suction valve FCV-73-40. System operation continues with the use of the HPCI booster pump to draw suction from the suppression pool.

This PRA-based HPCI failure mode has become less important as a result of changes in the BWR Emergency Procedure Guidelines which generally advocate the continued use of water sources that are external to the containment. This avoids potential ECCS degradation due to high suppression pool temperature (high HPCI lube oil temperature) while simultaneously increasing suppression pool mass. Thus, an HPCI pump suction transfer to the suppression pool is no longer greatly desirable and especially in decay heat removal accident sequences, the operator would likely bypass the switchover logic to maintain the CST suction source, or realign to the CST if a switchover to the pool had occurred. Therefore, the inspection focus should be on the continued viable option of the CST as an i.,jection source during an accident sequence.

There were 2 LERs describing problems involving the CST/suppression pool switchover logic at the BFN plant since 1980. In the first event (LER 259/82-071), the condensate storage tank low level switches LS-73-56A and LS-73-56B failed to operate due to dirty and corroded activating plates of the level switches. The plate points were cleaned. The second event (LER 259/84-028) was related to the failure of the automatic CST/suppression pool tiansfer logic to perform its intended function during surveillance testing because of a dirty contact on the limit switch. Present surveillance practices at the BFN plant include testing and calibrating the CST low level and suppression pool high level transfer switches on a quarterly basis. During these surveillance inspections, the relays in the HPCI system logic are also actuated to satisfy overlap testing requirements which are used to demonstrate HPCI logic operability once per refueling outage. 
HPCl Failure No. 13 - Suppression Pool Suction Line Valves FCV-73-26 or FCV-73-27 Fail to Open

At the BFN plant, there are two 250 VDC powered suppression pool HPCI pump suction valves, FCV-73-26 and FCV-73-27, with a sheck valve CKV-73-517 in between them and this valve arrangement is in series with a hand control valve HCV-73-25. In the standby mode, the HPCI system is initially aligned to the eondensate storage tank (CST). The suppression pool suction valves are opened and the CST suction valve is closed on a CST low water level or a high suppression pool level signal. The importance of this failure mode has been diminished by the current emergency procedure guidelines which emphasize the continued use of external sources of water injection. This requires operator action to bypass the HPCI suppression pool switchover logic to prevent the opening of the suppression pool suction valves FCV-73-26 and FCV-73-27. This is especially true for the decay heat removal (non ATWS) sequence where it is likely that inventory makeup from the CST can be maintained.

In the industry-wide survey, there have been 6 failures of the suppression pool suction valve to open which represents about $4 \%$ of all HPCI system failures. All these failures occurred during system surveillances. For the BFN plant, one LER was identified that described the failure of the hand control valve in the suppression pool suction line. In this event (LER 259/87-027), the normally locked open hand control valve HCV-73-25 which isolates the suppression pool from the first motor operated suppression pool isolation valve FCV-73-26 during layup was found in a failed closed position (as observed through a borescope) with the stem separated from the valve disc. The failure was attributed to tensile overload on 3 of the 4 bolts which hold the key attachment between the shaft and the disc of the valve. The bolts were replaced with stainless steel bolts. Current surveillance practices at the BFN plant include verifying the normally open position of this valve. The RCM program schedule has recommendations to replace this valve with a newer design. As an interim measure, this valve is inspected at each refueling outage for signs of corrosion and appropriate maintenance actions are taken to correct any identified problems.

\section{HPCI Failure No. 14 - Minimum Flow Valve FCV-73-30 Fails to Open}

The minimum flow bypass line is provided for pump protection. The bypass valve, FCV-73-30, automatically opens on a low flow signal of $600 \mathrm{gpm}$ or less tlow when the pump discharge pressure is greater than $125 \mathrm{psig}$. When the bypass line is open, pump flow is directed to the suppression pool. The valve automatically closes on a high flow signal of $1200 \mathrm{gpm}$ or more flow. During an actual system demand, failure of the minimum flow valve to open is important only when the opening of the pump discharge valve FCV-73-44 is significantly delayed. In probabilistic terms, this combination of events is generally not risk significant. With regard to system operation and testing in the minimum flow mode, the licensee response to NRC Bulletin $88-04^{19}$ should be reviewed to determine the adequacy of the design of the minimum flow bypass line. Unless there is a design concern or a recurring problem with either component, inspection attention may be minimized in this area.

At the BFN plant, there were no LERs in this failure category identified over the 12 year review period. Although the HPCI minimum flow valve has not been prone to failures, current surveillance practices at the BFN plant include verifying proper operation of this valve during performance of valve stroke time testing and tlowrate testing activities. 


\section{Other Failure Modes}

The industry-wide Operating Experience Review did not identify any $\mathrm{HPCI}$ system failures for the following PRA-based failure modes:

- Normally Open Pump Discharge Valve FCV-73-34 Fails Closed or is Plugged

- Pump Discharge Check Valve FCV-73-45 Fails to Open

- CST Suction Line Check Valve CKV-73-505 Fails to Open

- CST Suction Line Manual Valve HCV-2-705 Plugged

- Normally Open CST Pump Suction Valve FCV-73-40 Fails Closed or Is Plugged

- Suppression Pool Suction Line Check Valve CKV-73-517 Fails to Open

- Normally Open Steam Line Containment Isolation Valve FCV-73-2 or FCV-73-3 Fails Closed

- Steam Line Drain Pot Malfunctions

- Turbine Exhaust Line Vacuum Breaker Valves Fail to Operate

- Suction Strainer Plugged

The PRA-based prioritization of HPCI failure modes have a good eorrelation with the actual industry-wide experience of $\mathrm{HPCl}$ system failures. With the exception of the first failure mode listed above for the pump discharge valve FCV-73-34, all of the HPCI faults listed above have been considered as "low importance" failure events in the PRA-based rankings of Section 4.

In the LER survey, one LER event involving failure of the steam line isolation valve was identified for the BFN plant. In this event (LER 296/84-013), the HPCI outboard steam line isolation valve FCV-73-3 could not be opened electrically because the motor pinion gears had been installed backwards. Current surveillance practices at the BFN plant include verifying proper operation of all HPCI system flow/pressure control valves (e.g., FCV-73-19, FCV-73-43, PCV-73501, PCV-73-502, etc.) during the performance of $\mathrm{HPCl}$ system flow rate tests.

\subsection{Site Visit Observations}

During a plant site visit to the BFN plant, discussions on various aspects of operation, maintenance and surveillance of the HPCI system to ensure reliable system performance were held with licensee representatives. Recent or planned modifications to prevent or eliminate problems identitied in previously issued LERs were discussed. The recent or planned modifications to upgrade the HPCI system at the BFN plant are:

a) The governor control system has been redesigned and upgraded with new components such as a new overspeed test controller in place of the original bias speed setting potentiometer, new and more reliable $24 / 48 \mathrm{Vdc}$ power supplies, and new replacement of the ramp generator/signal converter (RGSC) box, EGM controller, speed sensor and cable assembly;

b) The EGM control panel has been relocated from the turbine skid to the HPCI room wall to eliminate the vibration effects of the skid environment as well as allowing ease of maintenance;

c) Seismic restraints has been added to the turbine skid piping to improve the margin of safety and seismic qualifications; 
d) Existing copper piping for the auxiliary oil supply has been replaced with stainless steel to be compatible with correct material requirements;

c) Control power supply from the HPCI "Topaz" inverter has been replaced with a direct connection to the Division II 120 Vac Uninterruptable Power Supply (UPS) system used by the analog trip system;

f) A one-inch relief valve (2-RFV-73-506) has been installed in the HPCI booster pump suction piping to ensure the mitigation of overpressurization events; and

g) The tappet assembly on the overspeed trip wals being replaced with a new Dresser-Rand design based on the recommendation of GE Service Information Letter (SIL) No, 392, Revision 1.

In addition to the above moditicatons, the licensec have established a reliability-centered maintenance (RCM) program for maintenance of the HPCI system and a recommended surveillance program per ASME Section XI requirements to check limit switch settings of all relevant HPCl system valves. Furthermore, the licensec has instituted a performance monitoring program to assure contamination free oil in the lube oil reservoir supply and introduced requirements in mechanical maintenance procedures (MMI-23) to include quality control inspections of all pertinent HPCl system repair work. It is noted that there is a concerted effort at the BFN plant to upgrade the HPCI system control equipment that would preclude the effects of component obsolescence, improve system reliability and thus, enhance HPCI system availability.

\subsection{Contribution of Human Errors to System Unilvailability}

The potential for human crror exists for activities involving maintenance, calibration, surveillance, and operation of plant systems. In PRAs, the influence of operator error on plant risks is typically modeled both in fault trees (system failure diagrams) and in the event trees that delincate the postulated sequenees. As such, these human errors are usually defined as gross actions that can cause complete failure of a system. Typical human errors considered in PRAs that affect $\mathrm{HPCI}$ system availability are:

a) Failure to manually start the high pressure injection system after automatic injection fails,

b) Operator failure to transfier pump suction from the CST to the suppression pool after a pump trip on low suction due to CST unavailability,

c) Failure to provide makeup to the CST during an ATWS event,

d) Failure to transter pump suction from the suppression pool to the CST during an event in which high suppression pool temperatures are reached (e.g., during an ATWS event, or during a non-ATWS event where there is failure of suppression pool cooling),

c) Failure to override the HPCI high-temperature isolation logic (for station blackout sequences), 
1) Miscalibration of HPCI system sensors that disables system actuation, caluses system isolation on erroneous high RPV level indication, or results in false system isolation signals, and

g) Failure to reset the HPCI system for operation after testing or maintenance.

Except for the last two listed items, all these human crrors are either: (i) conditional crrors, i.e., mistakes made within the context of an HPCI system failure or isolation (errors a and b), or (ii) event specific errors (items $c, d$ and $e$ ). These types of human errors make direct observation of their occurrence unlikely. Therefore, the potential for these human errors can only be evaluated indirectly by a review of the licensee procedures and observation of operator performance at a simulator.

The last two types of human errors can oceur during normal operation and thus, are more easily inspectable. NRC Resident Inspectors routincly examine surveillance, calibration and maintenance practices and procedures, and perform main control room and plant lineup veritications of ECCS. HPCI system operability is confirmed by checking the steam supply and exhaust lineup, pump suction and discharge lineups, and the control function settings (hand/auto station in automatic mode).

In addition to the examination of licensee practices and procedures, the application of insights from the review of industry-wide experience can help reduce a significant portion of the HPCI system unavailability due to human error contributions. In the reactive mode, a thorough root cause analysis and suitable corrective measures can prevent similar oceurrenees in the future.

In the LER survey of HPCI system-related failure events at the BFN plant, five LERs describing failure events caused by human errors were identified. These 5 LERs are brietly summarized below:

(a) LER 259/85-(056 described a configuration problem in which the normal and alternate control power supplies to the $4 \mathrm{kV}$ shutdown board " $\mathrm{A}$ " were found to be reversed as a result of a wiring error that was attributed to personnel error during the initial installation of the shutdown battery board.

(b) LER 259/82-(032 described the simultancous unavailability of satety systems due to procedural deficiency and lack of communication, when the power supply breakers for train "A" RHR and core spray pump motors were racked out during the performance of a test on $4 \mathrm{kV}$ relays which rendered the safety-related pumps and HPCI system inoperable.

(c) LER 260/82-016 reported that the HPCI system wals rendered inoperable when the HPCI system lubricating oil reservoir was found to be almost empty because the reservoir drain valve was opened 1 and $1 / 2$ turns as a result of personnel crror.

(d) LER 260/83-(28 described a HPCI turbine eontrol valve failure to open because of a rod misadjustment.

(c) LER 296/84-013 described the inability of HPCI outhoard steam isolation valve FCV-73-3 to be opened electrically because the motor pinion gears had been installed backwards. 
Present practices at the BFN plant include incorporating lessons learned from LER analyses into the training programs for maintenance and surveillance test personnel, and utiizing insights from root cause analyses to resolve a mixed spectrum of potential problems. A Site Standard Practice document (SSP-12.9) provides guidance for the performance of incident investigations and root cause analysis of signiticant and some non-significant human errors related to the operation, maintenance and surveillance of the HPCl system. This document also provides the requirement for mandatory training of at least one member of the incident investigation team in root cause analysis techniques. The implementation of this site procedure has proved to be useful in identifying and rectifying problems.

\subsection{Additional System Considerations}

The LER survey of industry-wide experience has identified several other HPCl system considerations that could impact the overall risk of a plant. These considerations are discussed in the following subsections with any related BFN plant experience.

\subsubsection{LOCAs Outside Containment}

Unlike the HPCI system failure modes discussed previously, that result in unavailability of the system for core damage mitigation purposes, failures in the HPCI system boundary can be potentia! initiators of a LOCA outside containment. The industry survey identified degradations of the steamline isolation function and pump suction line overpressurizations as potential causes. Examples of steam line isolation problems include:

- a steamline differential pressure transmitter with a non-conservative setting, and

- an inboard containment isolation valve that failed to close.

Examples of pump suction line overpressurizations include:

- a slow closure of the pump discharge check valve that caused a pressure surge after a turbine trip, and

- a water hammer caused by steam void collapse following system initiation after feedwater backleakage elevated the temperature in the pump discharge line. (NRC IN 89-36 provides a discussion on elevalted temperatures in ECCS systems. ${ }^{20}$ )

At the BFN plant, the main control room has analog indicating loops to provide indication of the HPCI booster pump suction pressure (PI.73-28A) and the main pump discharge pressure (PI-73-31A). Backleakage from the feedwater system would cause these pressures to increase noticeably and the instrumentation would alert operators to respond to the potential overpressurization problem.

In general, the potential event of $\mathrm{HPCl}$ system LOCA outside containment is considered to be a small contributor to the total core damage likelihood. The diversity of the steam line break 
detection logie and the downstream feedwalter sheck value redece the potential for an unisolated LOCA outside containment. The examples presented above are potential ancias for inspection to assure that plant design or operation does not increase the possible oceurrence of this initiator.

\subsubsection{Support Systems Required for HPCI System Operation}

The high pressure coolant injection system is dependent on other systems (ealled support systems) for sucecsstul (uperation. These systems are:

DC Power

Room Cooling

HPCI Actuation
For system control, pump operation and valve movement.

For HPCI pump room cooling to support long term operations. This tunction requires service water (for cooling) and $\mathrm{AC}$ power supply for the fitn motor.

RPV level and primary containment pressure instrumentation for system initiation and shutdown.

Review of the HPCl system operational history showed that the intluence of reliable support systems on HPCl system availability was obviously signiticant. The loss or degradation of the DC battery or DC bus that provides control power to the HPCl system hats a straightforward effect. Beside: battery charger problems or inadvertent fuse openings, the unusual DC system problems included a battery degradation due to corrosion of the eell plates. The suspected cause was a galvanic reaction due to plate weld metal impurities. Another concern is insufficient voltage at the load eenters during degraded voltage eonditions which could trip the station inverters or fail MOVs (e.g., Browns Ferry 1, Brunswick 1 \& 2 and Nine Mile Point 1 events). This problem would be of particular concern during a loss of offsite power or a station blackout event. A BFN plant LER (LER 259/85-(032) reported the potential for electrical support system failures.

The effects of loss of $\mathrm{HPCl}$ room cooling on continued $\mathrm{HPCl}$ system operation are not very clear. Tolerable ambient conditions in the HPCI room is typically required to support long term $\mathrm{HPCl}$ system operation. Besides random failures which can occur at any time, there is one accident sequence specific effect that should be examined. During station blackout conditions, the HPCl room temperatures may increase substantially when continued $\mathrm{HPCl}$ system operation is most critical. At the BFN plant, the HPCI pump room does not have any room coolers. However, it is open to the adjacent RHR quadrangle area which is ventilated automatically by room coolers that are activated on high temperature in the area. Although there are plant procedures (2-EOI-3) to address proper operator response to lower any high temperature con. ion in the HPCI room, the licensec actions to preserve HPCl system operation should be examined. The licensee should have acceptable pump room and steam line temperature calculations, or have other proceduralized provisions (e.g., bypass high temperature isolation) to assure long term HPCI system operability.

The RPV level or high drywell pressure instrumentation is required for actuation of various ECCS systems including the HPCI system. The operating experience review did not have any pertinent examples of failures of the ECCS actuation logic which directly affected HPCI system operation. This is because the ECCS actuation instrumentation logic does not activate the $\mathrm{HPCI}$ system directly. The initiation signal to start the HPCI system automatically is relayed via the 
Shared Actuation Instrumentation signals gencrated to actuate intermediate ECCS systems in response to plant abnormal conditions.

In summary, support system malfunctions sometimes cint impact HPCI system uperation in a subtle manner. Within the context of specific alecident scentrios, the incipient failure of these support systems may render the front-line system inoperable. The inspector(s) should verify that licensece personnel are aware of these support system dependencies and contirm that compensating measures are adequate to address this concern. Presently, operator training lessons at the BFN plant include examples and descriptions of conseyuences of support system interactions problems that may cause HPCI system inoperability. Awareness of support systems interaction problems are further ested and reinfored by simulator training exercise's fo ennance proper diagnosis of the effects of the systems interaction scenarios.

\subsubsection{Simultaneous Unavailability of Multiple Systems:}

Multiple system unavailability of certion functionally related systems is a major concern becaluse of the increased risk associated with continued operation. Although standard technical specitication 3.().3 provides the operational constraints of limit the risk exposure somewhat, the lieensee should avoid planned multiple system outiges if pussible.

Within the context of the accident sequences discusscel previously (in Section 3), unavailability of certain combinations of systems results in a relatively large risk of core damage. For example, the HPCl system operating experience review found nine L.ERs that documented simultaneous unavailability of HPCI and RCIC systems. During such outinge periods, the probability of eore damage becomes very much higher due to the increased likelihoods of accidene seguences in which $\mathrm{HPCl}$ and RCIC systems are required for mitigation purposes. This would include all of the accident seenarios described in the Accident Sequence Description except for the "Unisolated LOCA Outside Containment" sequence. Unavailability of the HPCl system and an emergency diesel generator together would have a similar impact on overall plant risk. Additionally, the simultancous unavailability of the HPCI system and ADS (one LER describes this oceurrenee during logic testing) would have a signiticant impact on the progression of Seyuence 1. "Loss of High Pressure Injection and Failure to Depressurize".

Although some of these LER examples of multiple system univislibility were due to random failures, the majority of such outages involve licensec decisions a disible a system for surveillance tests when another eritical system is not operable. At the BFN plint. Technical Specifieation 3.5.e items 2 \& 3 forbid multiple systems to become simultineously univailable during normal plant uperation." Plant procedures SSP-7.1 "Work Control" and SSP-7.2 "Outage Management" provide guidance to the Operations staff to ensure that Technical Specifications for the BFN plant units are maintained when plant eonditions require outage work to be performed. If one system is out of service and another system unexpectedly becomes inoperable, the Operations Shift Supervisor is respensible for placing the plant in sate shutdown conditions per SSP 12.1 "Conduct of Operations" in conformance with Technical Specificitions.

In the L.ER survey, two LERs wese found to describe aceurrences of simultanceus unavailability of HPCI and other satety systems at the BFN plamt. In the first event (LER 259/82. (32), the power supply breakers for the irain "A" RHR and core splay pum, motors were racked out during the performance of a surveillance test on $4 \mathrm{kV}$ relays which rendered the satfety pumps 
and the HPCI system incperable. The second event (LER 246/8.5-1013) wats related fo the IIPCI system being declared inoperable as a result of failing to reach ratted flow in 25 seconds (actual time taken was 35 seconds) due to an incorrectly set limit switch which starts the HPCl auxiliary oil p' np, and a failed restart of the RCIC pump during a subseguent RCIC pump operability performance test to sittisty technical specification reguirements. The RCIC pump failed to restart hecause the limitorgue operater of a motoresoperated steam isolition valve would not reopen to allow steam supply to the pump turbine.

At the BFN plant, administrative control procedures prevent unavailability of multiple systems due to testing and maintenance activities. The operations staft is required fo assure that no licensed conditions are violated when remeising a system from service. Furthermore, all repair work or testing on a system must be approned by the operations statt in alcoordatne with procedure SSP. 7.1 "Work Control" and procedure SSP.K.I "Conduct of 'Testing." 


\section{SIMMARY}

This System Risk-Based Inspection Giucke (System RIG) has heen develepled as an aid lo HPC I system inspections at the Browns levry Nucleat Plant. The document presents a risk based discussion of the role of the IIPC' system in accident mitigation and provides a cantaleguce of PRA. hased HPCl system failure modes. In addition, the system RIC uses information from industry "perating experience, including illustrattive examples, 10 angment the identifiention of the basice PRA failure modes. The risk-hased input and insights from the operating experience datahase have heen combined to develop a set of eomposife rankings of lailure modes for the HPCI system. Table 4.2 shows the ranking of these HPCl system failure modes. This information can be used to optimize NRC resoutes by properly allocalting proactive inspection efforts based on risk considerations and industry experience. In iddition, important component finules are summarized in Section 6 and the discussions of risk implications provide insights both for routine inspections and the "post mortems" conducted after the oceurrente of significant failures.

Review of the BFN plant HPCl system operational history has identitied the following component failure modes that experienced a high freguency of oceurenes:

- Curbine speced control fitults.

- inverter trips or lailures.

- Lurhine stop valve fitilures.

- Lurhine exhaust rupture disk fitlures, and

- CSTsuppression pool switchover logic firilures.

In addition, there was a relatively large number of HIPC I system lailure events due of test and maintenance activitics. The importance of kecping lhe HPCl system downtime due on T\&M activition as low as reasunahly possible is to minimize its dircet contribution to system univialahility. These areas should be given further allention during routine inspections and specialized inspection activities in the future.

As the BFN plant matures in its operating lifetime, the incidence of inadvertent HPCI system iscolations due to surveillance and calibrattion activities is expected an decrease heciousc of improved knowledge of the system. However, somponeme failures due to inging. related eanuses are expected to hecome a more significant contributor of the BFN plant HPCI system failure distribution. Review of industiy-wide operating experience has identified several HPCI system failure events due to component aging problems in the pump and turbine control systems all a fow older BWR plants including the Browns Ferry nuclear plant. It is noted that there is a concerted offort at the BFN plant to upgrade the HPC'I system sontrol eyuipment that would preclude the effects of eomponent obsolescence, improve system reliability and thus, enhance HPCI system availability. 
Recommendations have been made throughout this document regarding the emplansis or focus of inspection activities for the HPCl system at the BFN plant. Some of these suggestions are generic in nature, but some recommendations related to specitic maintenanece, testing, or operational activities conducted at the BH.N plant are made to assure that a highly reliable operation of the HPC system in mointitined. These recommendations condel also be useful to the

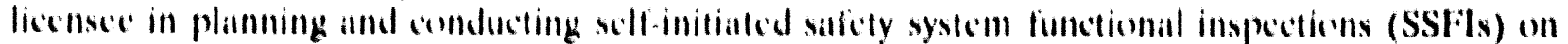
various safely systems including the IIPC'I system o ensure functional adequacy and operational readincess of a plant system. 


\section{REFERENCES}

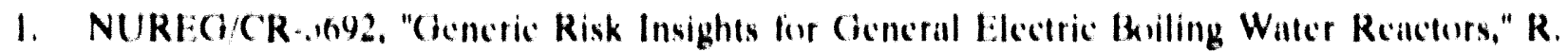
Travis, 't al. Muy, 1401.

2. NUREQ/CR.2812. "Interim Roliahility Evaluation Program: Analysis of the Browns Forry Nuclear Plant, Unit 1," S. Mays,ct al., July, 1482.

3. IPE Submittal, "Browns Ferry Nuclear Mant. Unit 2. Probabilistic Risk Asscessment," Soplember, 1942.

4. Shorcham Nucluar Power Station Probabilistic Risk Asscssment, Docket No. 50).322, Ionng Island Lighting Company, Junc, 198.3.

5. NRC Casc Study Repurt, AEOD/C\$(12, "Overpressurization of Emergency Core Cowling Systems in Builing Watcer Renctors," Peter I am. September, 1985.

6. Brookhaven National Laboratory (BNL.) Technical Ropert A-34.53.87.5 "Cirand Culf Nuclear Station Unit I. PRA-Bascd System Inspection Plans," J, Usher, et al., September, 1987.

7. BNL Technical Report A-345.3-87.2, "l imerick Cieneritting Stitton, Unit 1, PRA-Bascd System Inspection Plans," A. Fresco, ct al., May. 1987.

8. BNI. Technical Report A.3453.87.3, "Shorcham Nuclear Power Station, PRA.Based System Inspection Plans," A. Fresco, cl al., Maly, IUk7.

9. BNI. Technical Repurt A.3k64.2. "Puach Butlom Alumic Power Stulion, Unit 2, PRA.Based System Inspection Plan," J. Usher, ct ill. April, IUSx.

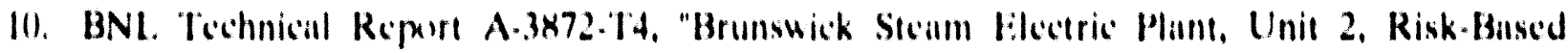

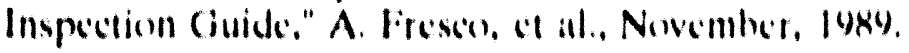

11. NRC Informattion Notice 66. 1.4. "PWR Auxiliary Fecdwater Pump Turbing Control Prohlems," March 10, 1986.

12. NRC Infurmation Nolice 86.14 Supplement 1. "Oversperel Trips of AlW. IIPC'I and RCIC Turhines." December 17, 1986: Supplement 2., August 26, 1991.

13. NRC AEOD Case Study Repurt C'612., "Operational Ixperience Involving Turbine Overspeced Trips," August, I986.

14. NRC Infurmattion Notice 91.51. "Inadequate Fusc (onntrol Programs," August 20. 1941.

19. NRC AEOD Technical Review Repure Ty(), "Broken Limiting Beam Balts in MPCI Terry Turbinc," April 18. I9k\%.

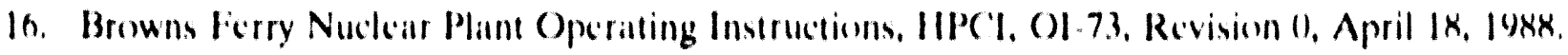


17. NRC AEOD R(port E402, "Willer Hammer in BWR High Pressure Conlant Injection Systcins," January, 1984.

18. NRC: Information Notice 82-26, "RCIC and HPCl Turbine Exhaust Check Valve Failures," July 22, 1482.

19. NR( Bulletin 8x.(14, "Pofential Safety Related Pump Less,," May 5. 1988.

20. NRC Information Notice 89.36, "Excessive Temperatures in Emergency Core Cooling System Piping Lenented Outside Containment," April 4. 1989.

21. Browns Ferry Nuclear Plant, Unit 2, Technical Specilications, Amendment No, 215, May 21, 1943.

\section{Additionil References}

A. Browns Ferry Nuclear Plant Licensed Operator Training Materials, HPCl System, OPL 171.(142, Revision 4. March 26, 1991.

B. GE Scrvice Information Letfer, SIL. No, 392, Revision 1, "Improved HPCl Turbine Mechanical-Hydraulic Trip Design," November 28, 199(). 


\section{APPENDIX A.1}

\section{SUMMARY OF INDUSTRY SURVEY OF HPCI OPERATING EXPERIENCE}

HPCI PUMP OR TURBINE FAILS TO START OR RUN

A.1 


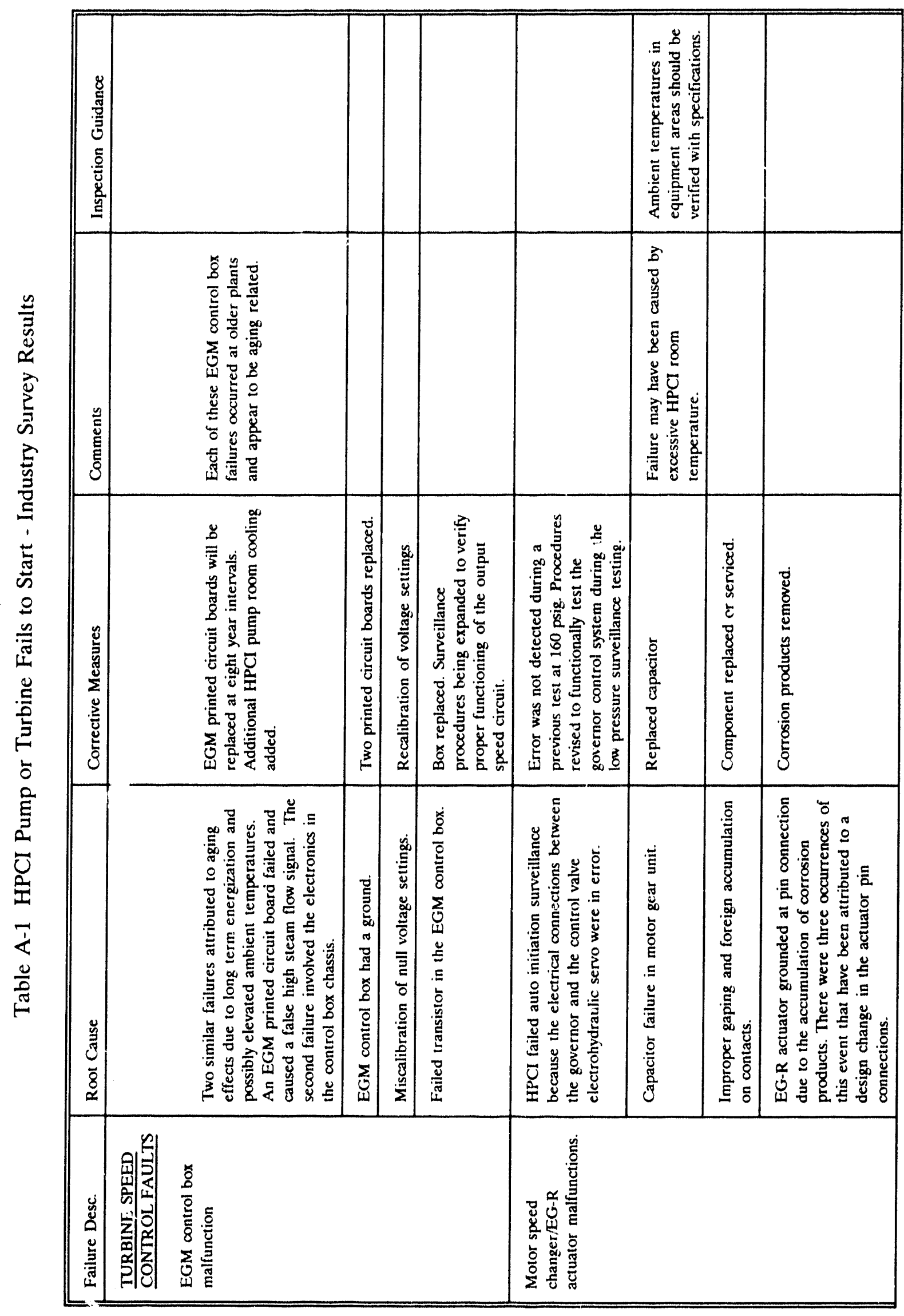




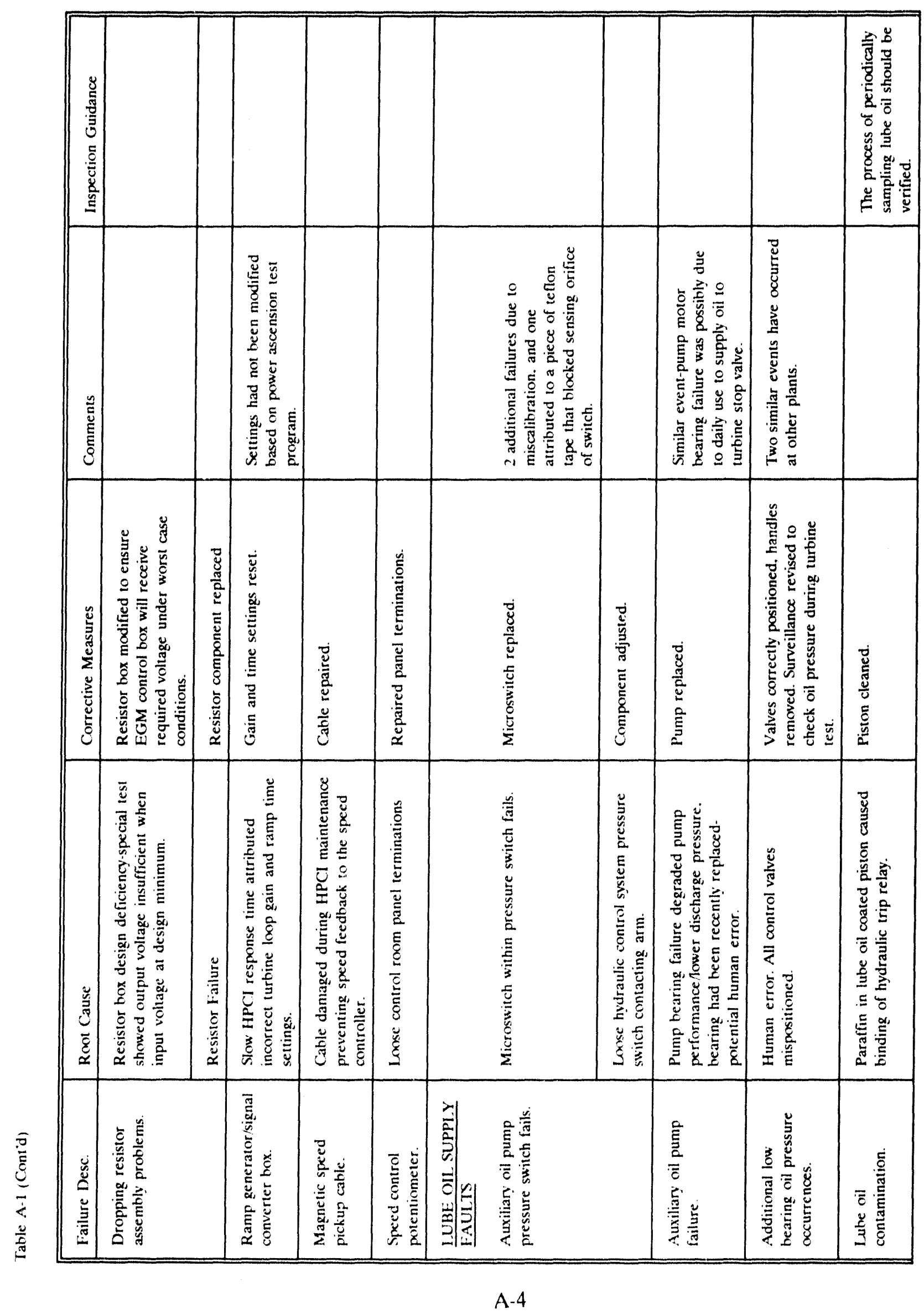




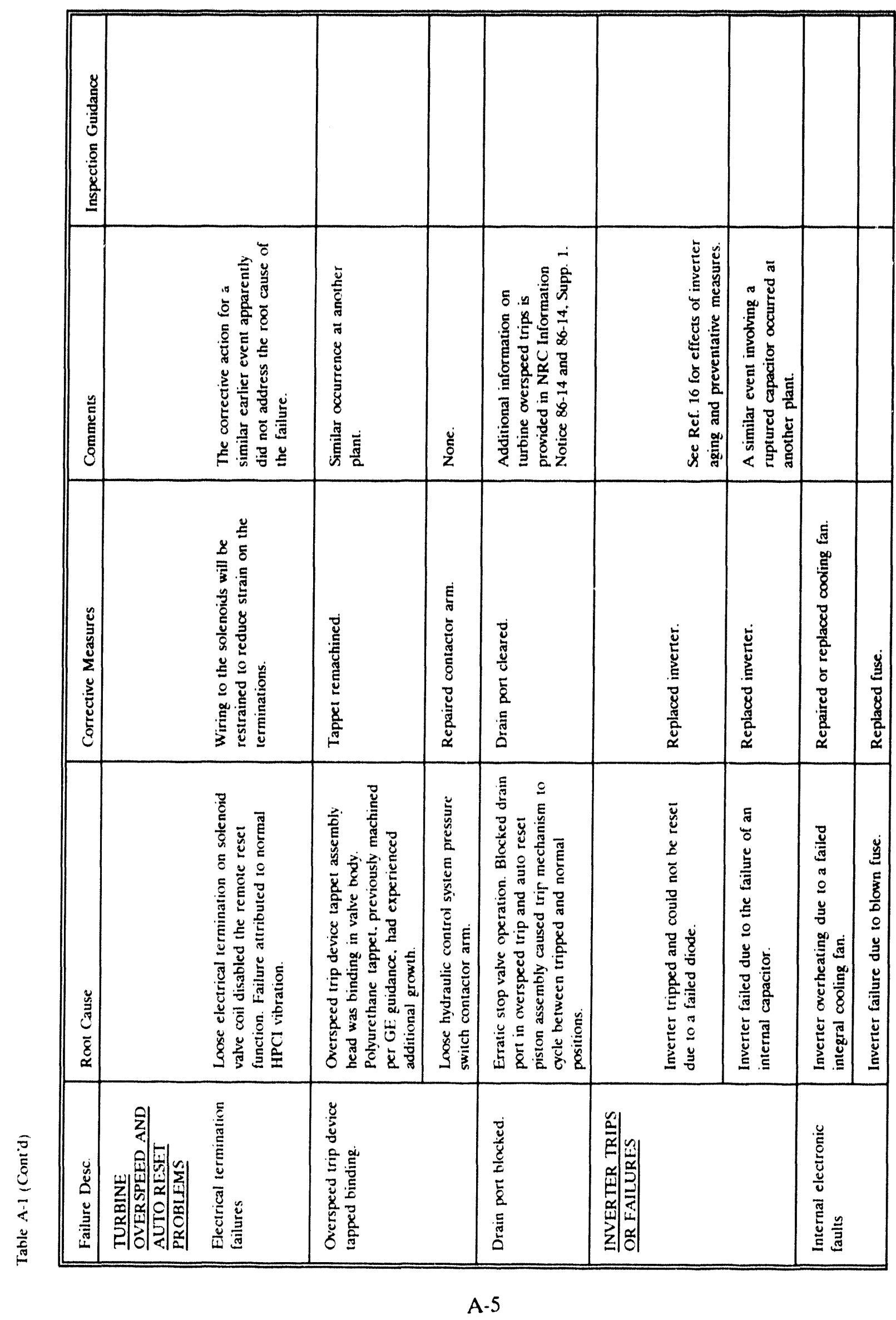




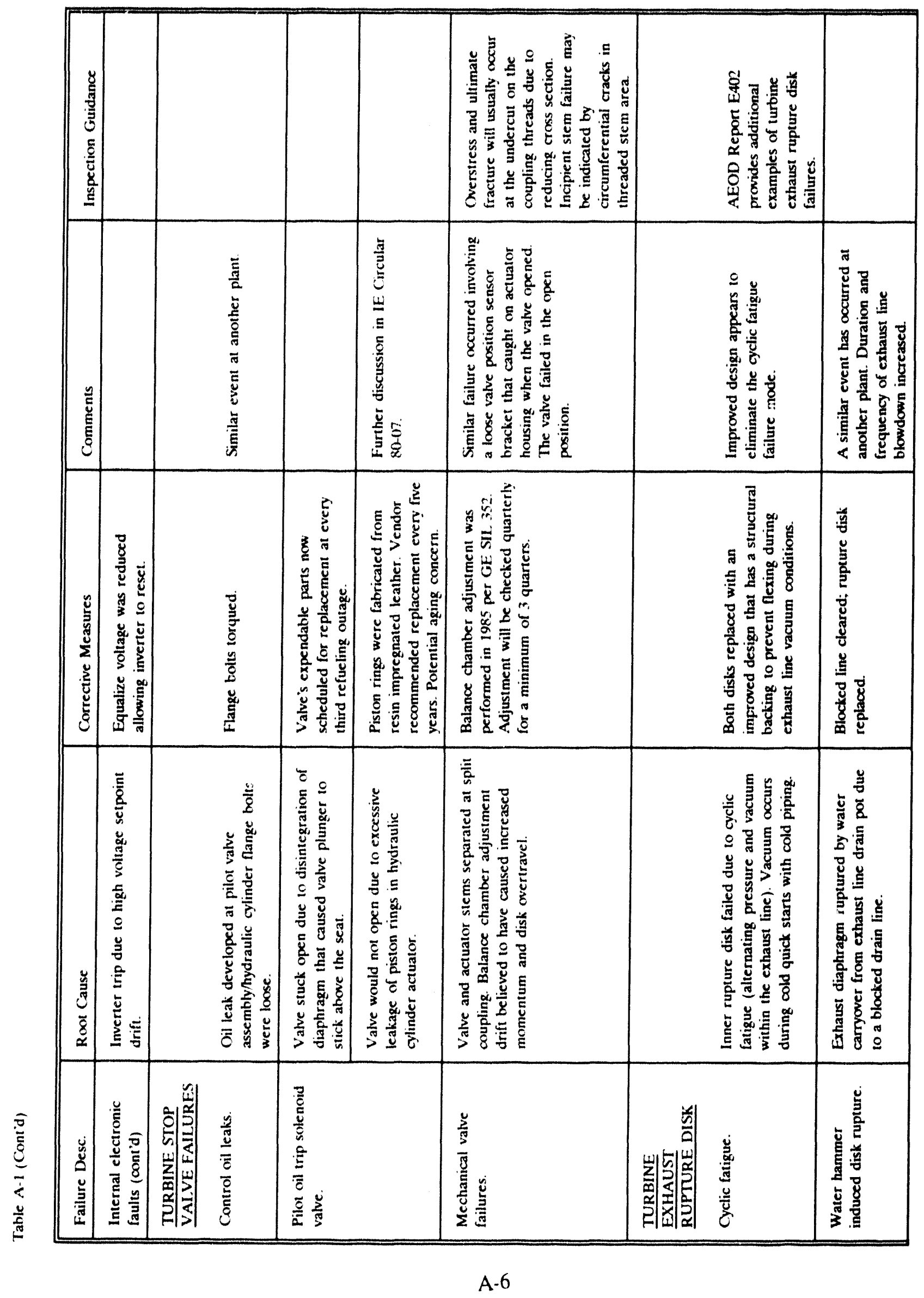




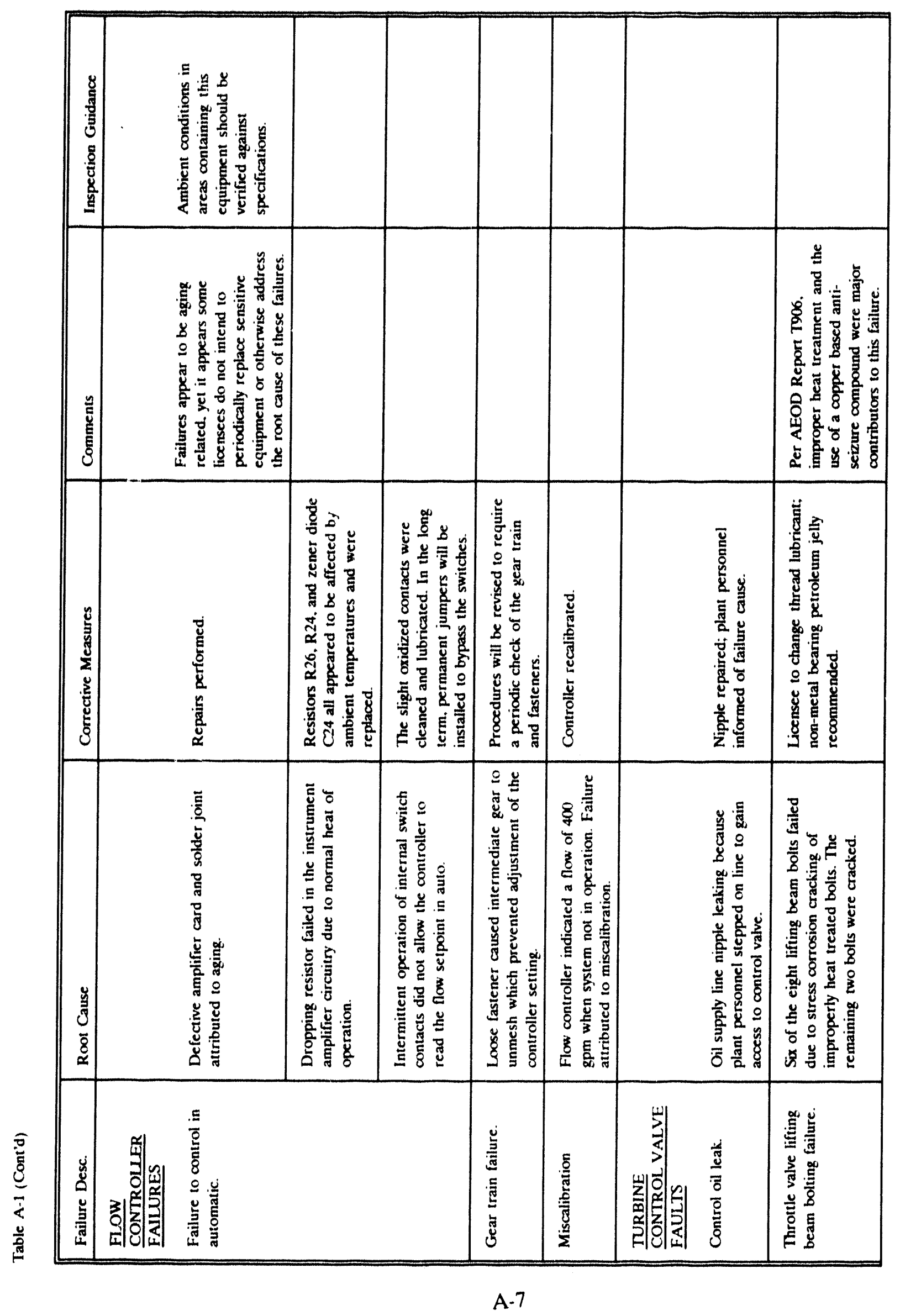




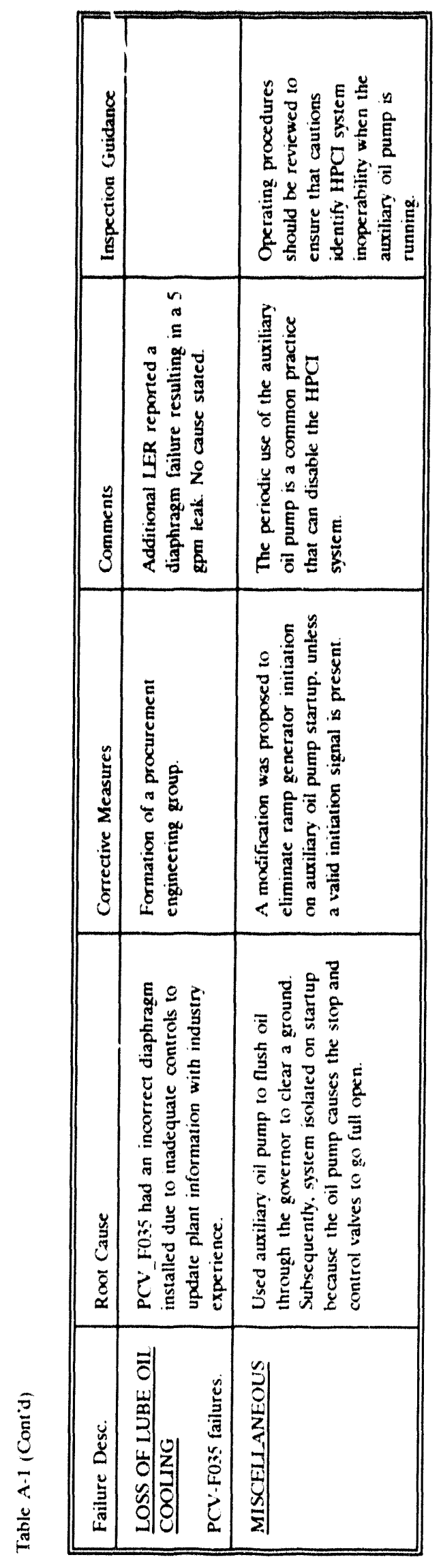

A. 8 


\section{APPENDIX A-2}

SELECTED EXAMPLES OF ADDITIONAL HPCI FAILURE

MODES IDENTIFIED DURING INDUSTRY SURVEY 


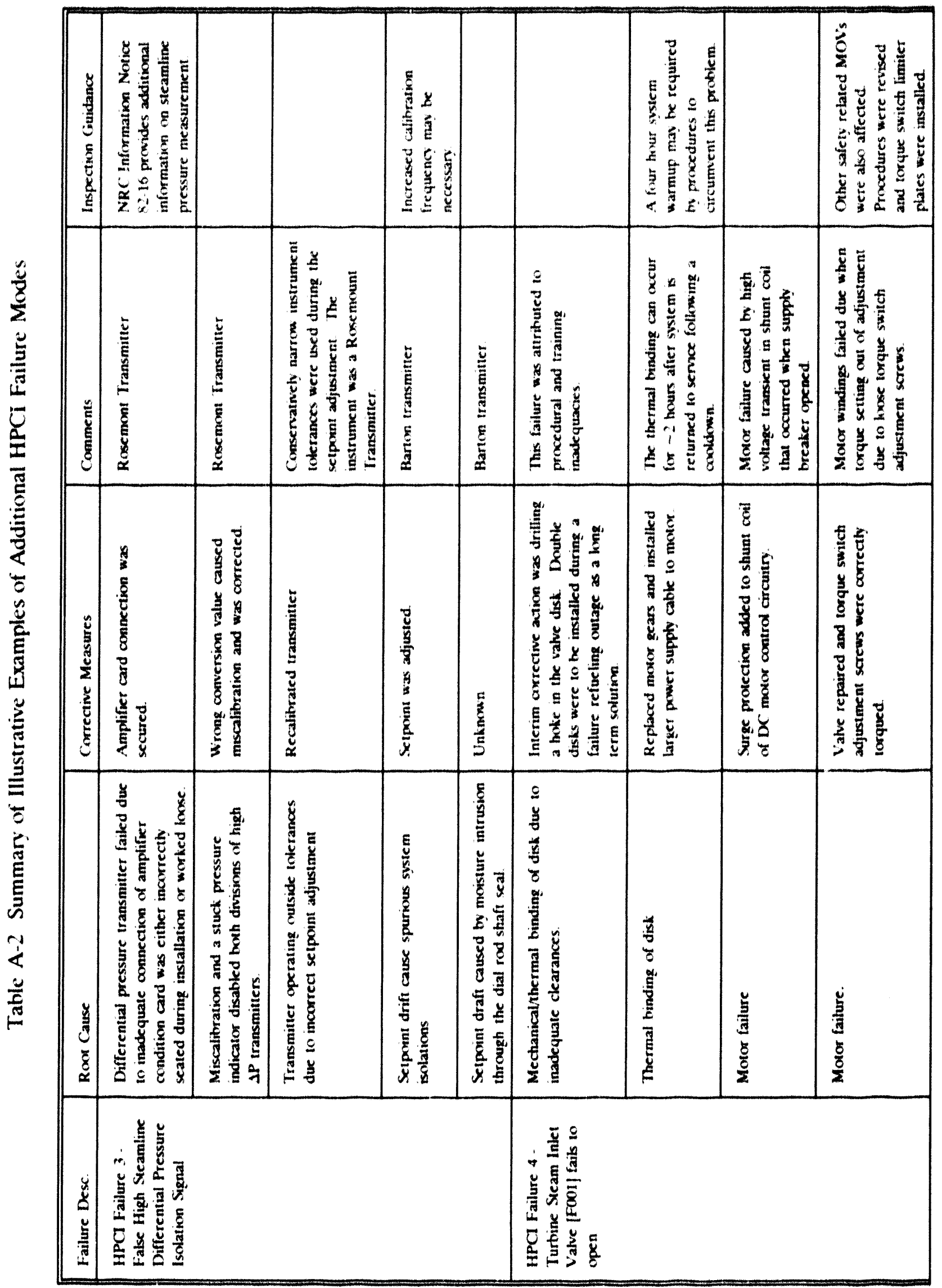




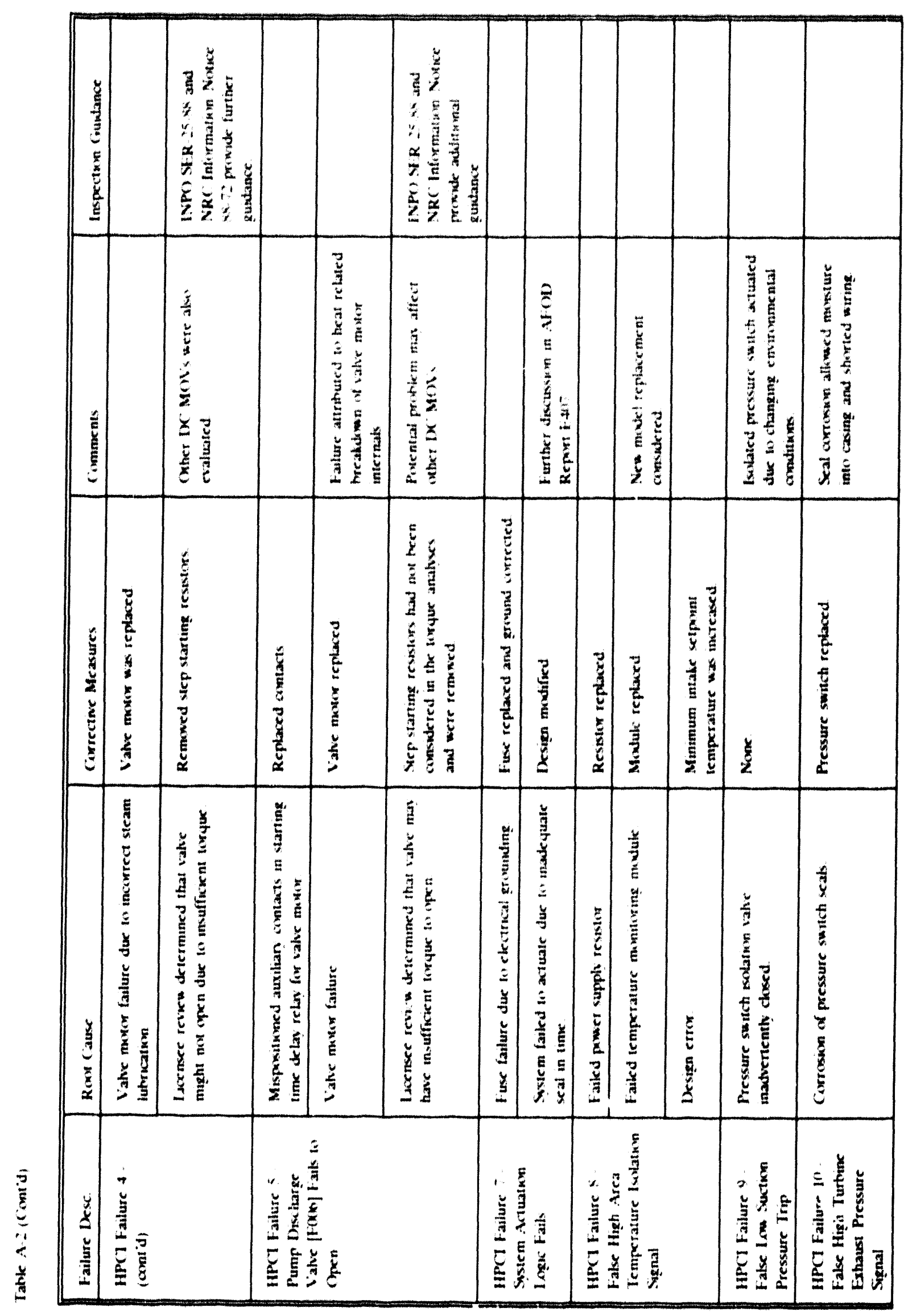

A. 12 


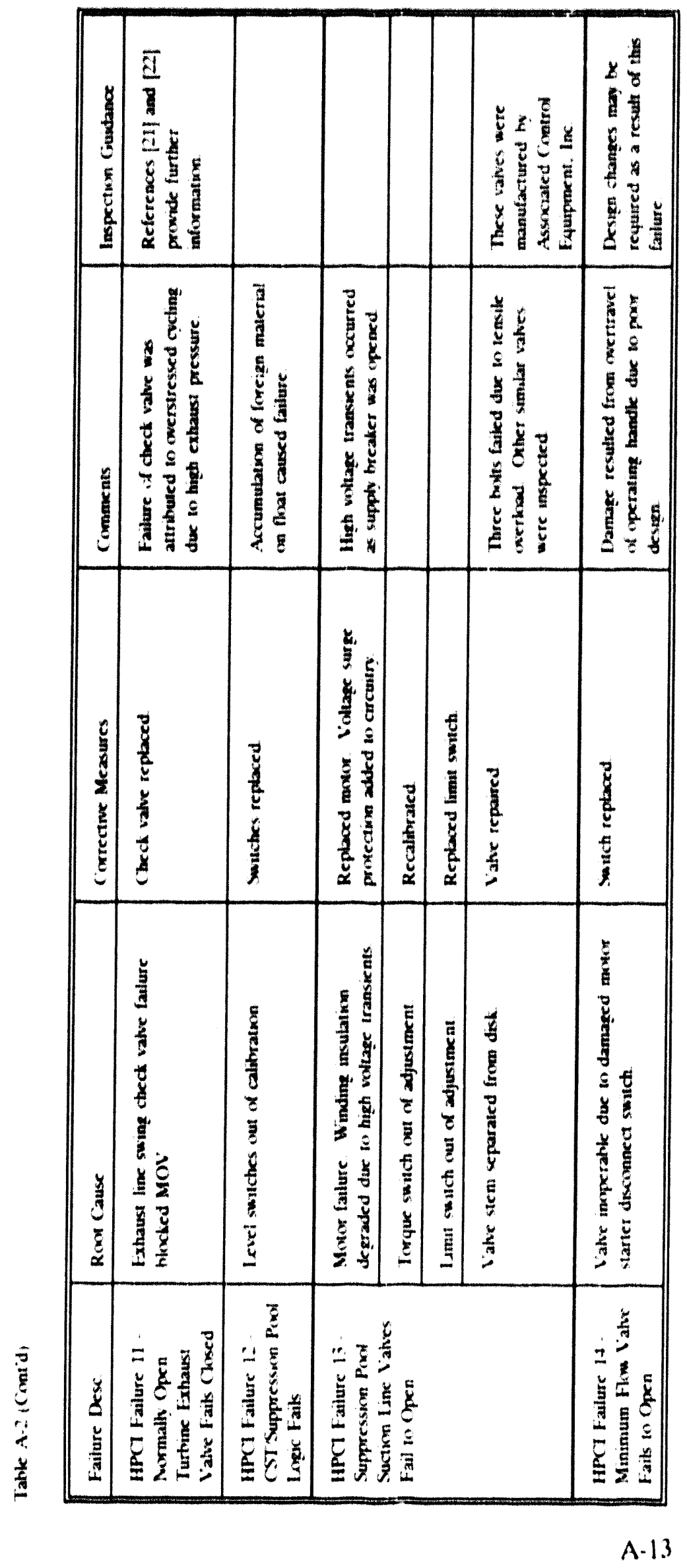


No. of Coniss

\section{OHFSITE}

U.S. Nuclear Regulatory

Commission

A. El Bassoni OWFN 10 E4

W. D. Becknor

OWFN 10 EA

K. Cimpo
OWFN 10 E4

10

J. Chung

OWHN 10 E4

F. Congel

OWFN III E4

B. K. Grimes

OWFN Y A2

J. N. Hannon

OWFN 13 E:21

\section{A. Hsii}

OWFN $13 \mathrm{DI}$

E. V. Imhro

OWFN Y AI

2

H. E. Polk

OWFN 121126

\section{No. at Conies}

2

B. Ciore

Pacific Northwest Lab.

Richland, WA Y9352

\section{ONSITE}

20 Brookhaven National Lab.

W. Gunther (10)

R. Hall

J. Higgins

J. Taylor

A. DiBinsio

Tochnical Publishing (5)

Nuclear Saficty Library (2)

2 J. Bickel

EO\&G Iduho, Inc.

P.O. B) 1625

Idaho Fulls, ID 8341 .

J. L.yons

Illinois Dept, of Nuclear Sinfety 10.35 Outer Park Drive

Springlicld, II. $627(14$

4 Browns Ferry Nuclear Power Station

Resident Inspector

4

U.S. Nuclear Regulatory

Commission - Region II

Regional Administrator 


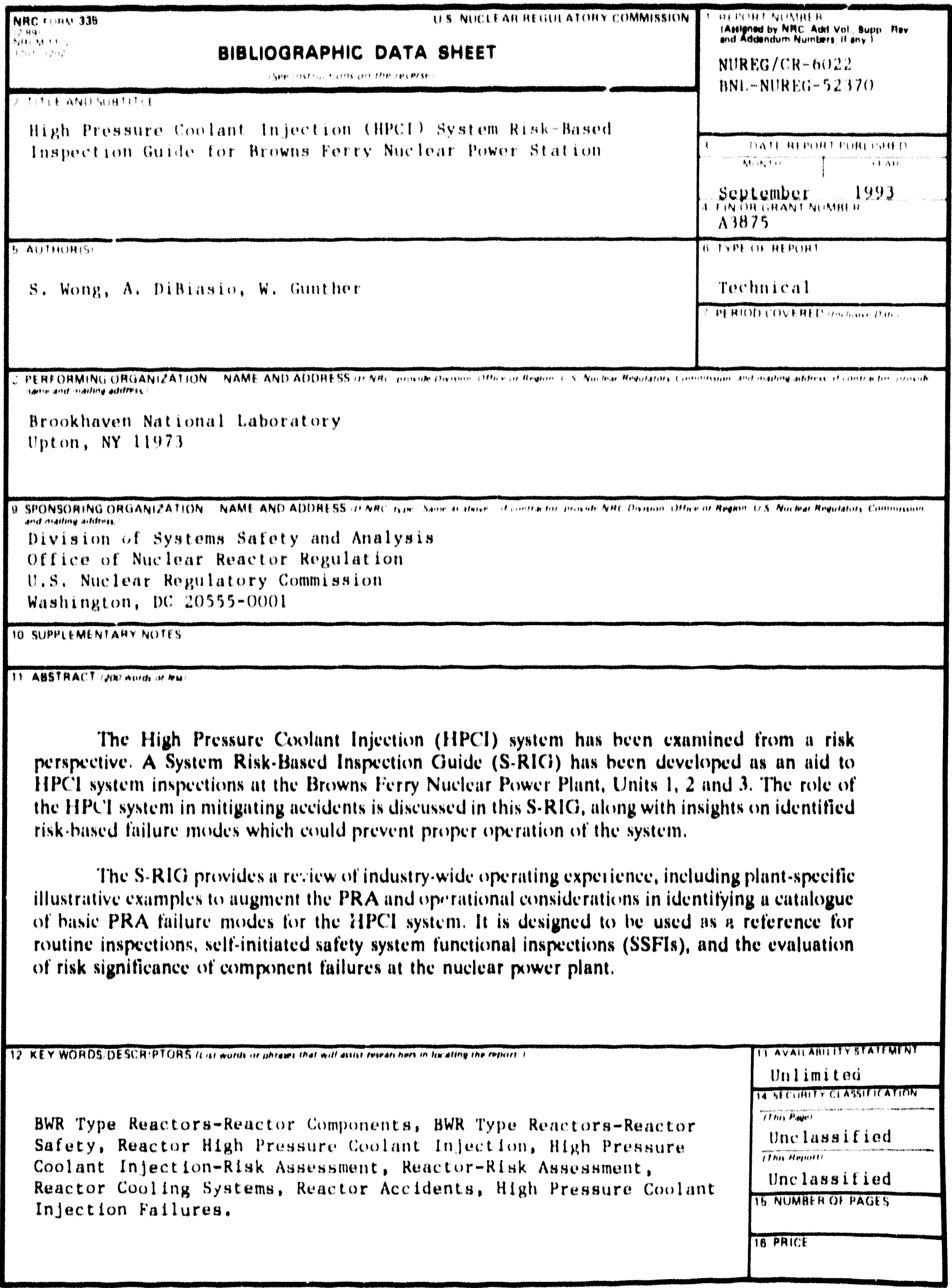




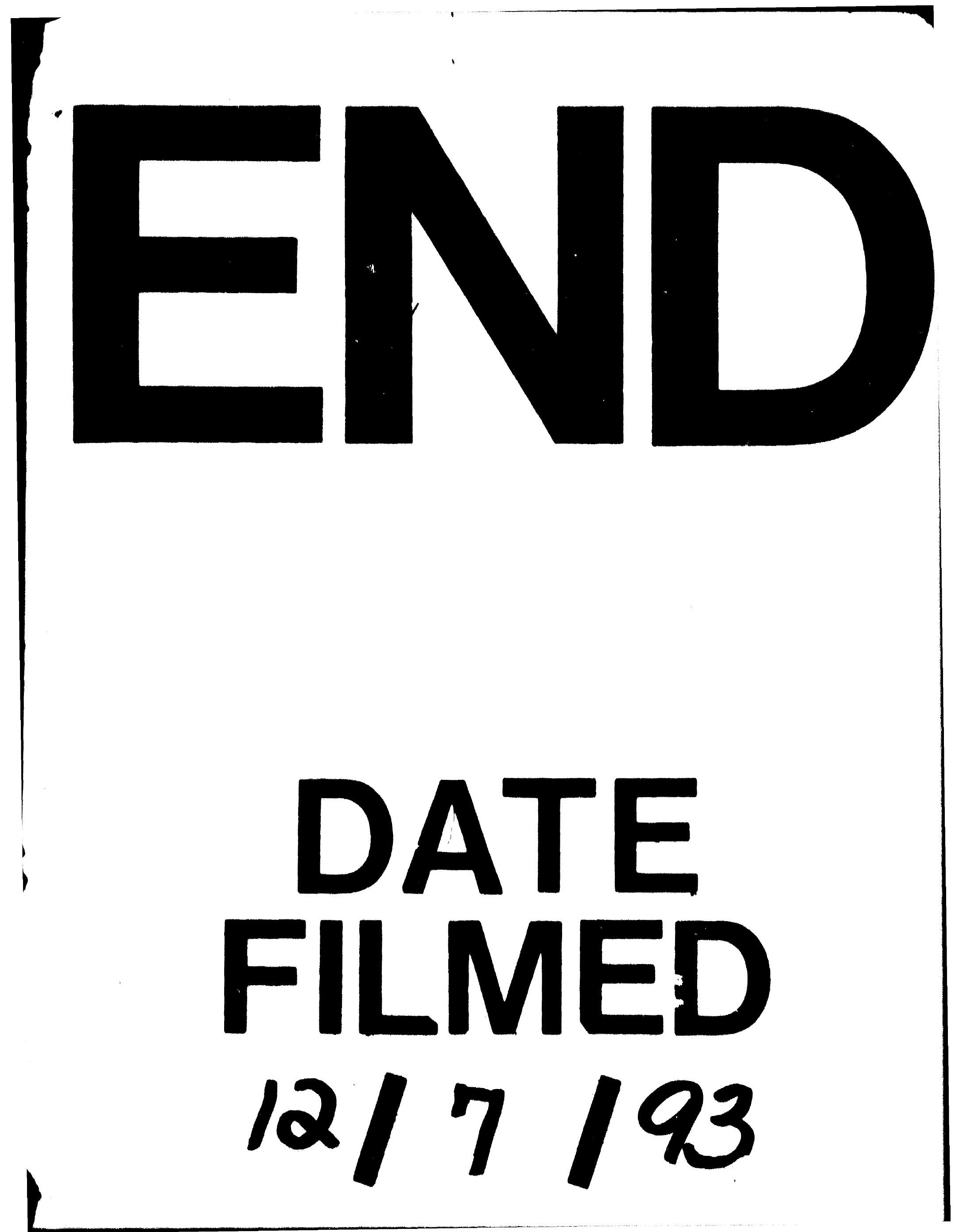




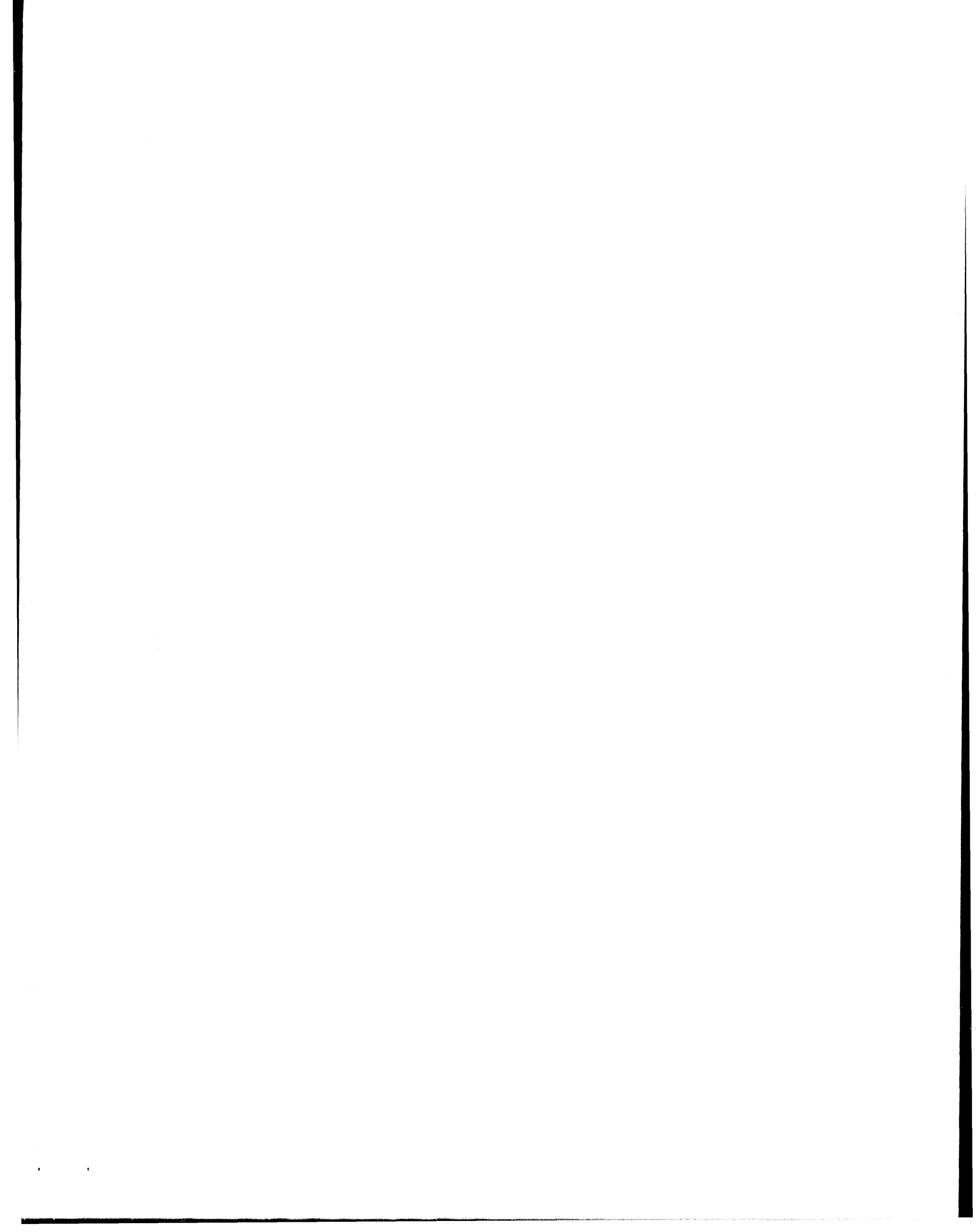

